Board of Governors of the Federal Reserve System

International Finance Discussion Papers

\author{
Number 956 \\ November 2008 \\ A Non-Random Walk Revisited: \\ Short- and Long-Term Memory in Asset Prices \\ by \\ Paul S. Eitelman \\ Justin T. Vitanza
}

NOTE: International Finance Discussion Papers are preliminary materials circulated to stimulate discussion and critical comment. References in publications to International Finance Discussion Papers (other than an acknowledgment that the writer has had access to unpublished material) should be cleared with the author or authors. Recent IFDPs are available on the Web at www.federalreserve.gov/pubs/ifdp/. This paper can be downloaded without charge from the Social Science Research Network electronic library at http://www.ssrn.com/ 


\title{
A Non-Random Walk Revisited: Short- and Long-Term Memory in Asset Prices*
}

\author{
Paul S. Eitelman \\ Justin T. Vitanza*
}

\begin{abstract}
In this paper, we test for short and long memory in asset prices across 44 emerging and industrialized economies. Using methodology from Lo and MacKinlay (1988) and Lo (1991), we find that markets with a poor Sharpe ratio are more likely to reject the random walk than better performing markets. We also make a methodological contribution. Contrary to the Baillie (1996) criticism, our long memory analysis suggests that the choice of a truncation lag is not as important as one might initially believe. Tests that reject the null hypothesis tend to do so across any reasonable choice in lag.
\end{abstract}

Keywords: random walk, long-range dependence, equities, commodities, exchange rates JEL Codes: E30, G14

* Author notes: We appreciate the comments of Shaghil Ahmed, Brett Berger, Dale Henderson, Erik Hjalmarsson, Andrea Raffo, and Robert Vigfusson. Eitelman and Vitanza are research assistants in the Division of International Finance at the Federal Reserve Board. Corresponding Author: Paul Eitelman, Mail Stop 24, Federal Reserve Board, Washington, DC 20551 USA. Email: paul.s.eitelman@frb.gov. The views expressed in this paper are solely the responsibility of the authors and should not be interpreted as reflecting the views of the Board of Governors of the Federal Reserve System or of any other person associated with the Federal Reserve System. 


\section{Introduction}

This paper reexamines the possibility of both short- and long-term memory in asset returns. In a weak-form efficient market, all information contained in historical prices is instantaneously reflected in the current market price. This effectively precludes the opportunity to earn abnormal returns through a trend trading approach. However, some investment strategies are still dedicated to the research and exploitation of price trends. Given the continued use of technical analysis in financial economics, the random walk hypothesis deserves further empirical analysis. A random walk test indicates the existence of intertemporal dependence at some chosen lag. A rejection of the random walk hypothesis implies that a trend in asset prices, or memory, exists.

We make two main contributions to the literature. Using a uniquely large dataset ${ }^{1}$ of commodities and stock market indices from 44 emerging and industrial economies, we are able to compare the behavior of international asset prices. We first perform a random walk test on each market over several lags. Next, we calculate the Sharpe ratio. A regression of a dummy variable indicating whether or not the random walk was rejected on the Sharpe ratio revealed that markets with poorer risk-adjusted returns are more likely to reject the random walk hypothesis. This finding suggests that contrarian investment strategies, which look for undervalued assets in depressed markets, may offer the prudent investor an opportunity to beat the returns of standard equity indices.

Second, we test for long memory in asset returns using the Modified Rescaled Range (R/S) statistic developed by Lo (1991). Some criticisms of this test cite that there is no optimal method for choosing a truncation lag. Although this criticism is theoretically valid, the results of our analysis suggest that the choice of a truncation lag often has little bearing on the significance of results. We find mixed evidence of long memory in international equity markets. Of the advaned markets, only Denmark, Japan, Norway, and Sweden exhibit long memory. In the U.S. dollar foreign exchange markets, regional factors appear to be at play. We find that four of the six Latin American currencies studied in this paper (Argentina, Brazil, Chile, and Colombia) show long memory, whereas we fail to reject the null hypothesis for every advanced market currency and for most countries across Emerging Asia, the Middle East, and Africa. Of the 22 commodities evaluated in this paper, only soybeans and cattle show signs of long memory.

\footnotetext{
${ }^{1}$ The data are described in detail in Appendix 1.
} 


\subsection{A Brief History of Previous Literature}

Financial time series analysis focuses on the intertemporal dependencies of asset prices. Early asset pricing models were based on the assumptions that returns are identically and independently distributed (iid) with a log-normal distribution. Mandelbrot (1963) was among the first to show that the normal distribution does not adequately capture the "fat tails", or leptokurtosis, of returns. Engle (1982) and Bollerslev (1986) then identified the presence of time-varying conditional volatility, or "volatility clustering", in daily equity returns with their AutoRegressive Conditional Heteroscedasticity $(\mathrm{ARCH})$ class of models. Many subsequent studies have since confirmed these findings, and the assumption of iid-normal returns is now widely rejected in the literature.

The Random Walk Hypothesis posits that today's stock price is an unforecastable transformation of its previous value. Based on this argument, Malkiel (1973) and Sharpe (1991) conclude that passive, low cost index funds should outperform their actively managed counterparts by some function of the trading, administrative, and management expenses owed. More broadly, any effort to forecast asset prices that follow the random walk should be value-draining.

There is considerable debate among financial economists whether the random walk hypothesis holds. Early research into the random walk hypothesis assumed constant volatility in the residual term. Because of Engle's well-documented exposition on the conditional volatility of returns, a rejection of the random walk because of heteroscedasticity is of little interest. The more advanced Lo and MacKinlay (1988) heteroscedasticity-consistent methodology is invariant to ARCH processes.

Mandelbrot (1971) also discovered a new empirical property in the time series of asset prices: low frequency persistent temporal dependence (hereafter long memory). Long memory is commonly characterized by a slower-than-exponential rate of decay in the autocorrelation function. For example, Taylor (1986) and Ding, Granger and Engle (1993) found a hyperbolic rate of decay in the absolute value of asset returns. As pointed out in Lo (1991), long-term memory is troublesome because it is inconsistent with the continuous time stochastic processes employed in martingale methods for the pricing of options and futures contracts. Mandelbrot (1972) adapted a previously existing test to identify the presence of long memory. This test, rescaled range, was first introduced by the hydrologist Harold Hurst (1951) to identify long-term patterns in the discharge of the Nile River.

The rest of this paper is organized as follows: Section 2 describes the methodology and results for our short memory (random walk) analysis, as well as a discussion on the power of our chosen test statistic. Section 3 describes the methodology and results of our long memory analysis. Section 4 
concludes our paper and discusses practical applications for our findings in financial economics. The appendices provide a more detailed view of our data and results.

\section{Short Memory}

\subsection{Methodology}

First we denote $P_{t}$ as the index level at time $t$ and define the $\log$-price process $X_{t} \equiv \ln P_{t}$. The conventional form of the random walk is then given as

$$
X_{t}=\mu+X_{t-1}+\epsilon_{t}
$$

where $\mu$ is an arbitrary drift parameter, and $\epsilon_{t}$ is the random error term. The standard null hypothesis, $\mathrm{H}_{0}$, stipulates that the error terms $\epsilon_{t}$ are independently and identically distributed normal random variables with constant variance $\sigma_{o}^{2}$, or

$$
\mathrm{H}_{0}: \epsilon_{t} \operatorname{IID} N\left(0, \sigma_{o}^{2}\right)
$$

However, given the well-documented fact that financial time series deviate from normality, ${ }^{2}$ and the mounting evidence of volatility clustering shown first by Engle (1982) and Bollerslev (1986), a rejection of the random walk due to these factors would be of little interest. Therefore, we study the short memory processes of our variables using the Lo and MacKinlay (1988) variance ratio test. This test assumes that $X_{t}$ possesses uncorrelated increments, but it allows for more general forms of heteroscedasticity and relaxes the requirement for Gaussian increments.

The rest follows almost directly from the Lo and MacKinlay methodology. ${ }^{3}$ For $n q+1$ observations $\left[X_{0}, X_{1}, \ldots, X_{n q}\right]$, where $q$ is any integer greater than 1 , we define the asymptotic estimators of the mean and variance of returns, respectively:

$$
\hat{\mu} \equiv \frac{1}{n q} \sum_{k=1}^{n q}\left(X_{k}-X_{k-1}\right)=\frac{1}{n q}\left(X_{n q}-X_{0}\right)
$$

\footnotetext{
${ }^{2}$ See Appendix 2 for further evidence and summary statistics specific to our data set.

${ }^{3}$ Lo and MacKinlay convert their data from daily to weekly frequency to mitigate the biases introduced by nontrading, the bid-ask spread, and asynchronous prices. We deviate slightly from their method of frequency conversion. We calculate the weekly return for each series as the return from Wednesday's closing price to the following Wednesday's close. If the following Wednesday's price is missing, we use Tuesday's price. If Tuesday's price is also missing we use Monday's price, etc.
} 


$$
\bar{\sigma}_{a}^{2}=\frac{1}{n q-1} \sum_{k=1}^{n q}\left(X_{k}-X_{k-1}-\hat{\mu}\right)^{2} .
$$

We then define $\bar{M}_{r}(q)$ as the variance ratio that obtains

$$
\bar{M}_{r}(q) \stackrel{a}{=} \sum_{j=1}^{q-1} \frac{2(q-j)}{q} \hat{\rho}(j),
$$

where $\hat{\rho}(j)$ is the autocorrelation coefficient estimator. Note that when $q=2, \bar{M}_{r}(2)$ simplifies to the first-order autocorrelation coefficient, $\hat{\rho}(1)$. Continuing from theorem 3 of Lo and MacKinlay (1988), we define $\hat{\delta}(j)$ and $\hat{\theta}(q)$ as the heteroscedasticity-consistent estimators of the asymptotic variances of $\hat{\rho}(j)$ and $\bar{M}_{r}(q)$, respectively

$$
\begin{gathered}
\hat{\delta}(j)=\frac{n q \sum_{k=j+1}^{n q}\left(X_{k}-X_{k-1}-\hat{\mu}\right)^{2}\left(X_{k-j}-X_{k-j-1}-\hat{\mu}\right)^{2}}{\left[\sum_{k=1}^{n q}\left(X_{k}-X_{k-1}-\hat{\mu}\right)^{2}\right]^{2}} \\
\hat{\theta}(q) \equiv \sum_{j=1}^{q-1}\left[\frac{2(q-j)}{q}\right]^{2} \hat{\delta}(j) .
\end{gathered}
$$

The following test statistic $z^{*}(q)$ is asymptotically standard normal and is used to describe our empirical results in section 2.2. Note that q can be interpreted as the period for which the existence of memory is being tested.

$$
z^{*}(q) \equiv \frac{\sqrt{n q} \bar{M}_{r}(q)}{\sqrt{\hat{\theta}(q)}} \stackrel{a}{\sim} N(0,1) .
$$

This test statistic is ideal for evaluating the random walk hypothesis because it accounts for the volatility clustering inherent in asset prices. However, since the effective sample size decreases as $q$ gets larger, small-sample biases will skew this statistic at sufficiently large lags (Lo and MacKinlay, 1989).

\section{$2.2 \quad$ Results}

The results of our random walk study are shown in Appendix 3. The dashed orange and red lines represent 95 and 99 percent rejection levels of the heteroscedasticity-consistent random walk hypothesis test, respectively. $z^{*}$-values significantly greater than zero imply a positive persistence in the autocorrelation function for the time series at some lag, $q ; z^{*}$-values below the lower rejection 
band show a mean-reversion in the time series at that lag. This paper does not attempt to prove explanatory factors for any non-random processes identified herein; instead we reveal those areas where further fundamental analysis should prove fruitful for academics and practitioners. A few notable themes emerge.

In commodity markets, we find common trends within commodity groupings. Energy items, including crude oil, natural gas, and heating oil, exhibit mean reverting price behavior. This finding is consistent with recent work by Geman (2007). As in Bleaney and Greenaway (1993), we fail to reject the random walk hypothesis for each of the nine metals series in our study. The agricultural raw materials, namely cotton and rubber, show significant persistence in returns while the finished farm products are largely random. Soybean prices are the exception, however, as they are shown to deviate from the random walk.

We fail to reject the random walk hypothesis for U.S. foreign exchange markets. Our findings are consistent with Liu and He (1991), who used the same heteroscedasticity-consistent methodology. We find that the Yen-Dollar and Pound-Dollar rates each exhibit positive serial correlation, particularly for small $q$ values, whereas the random walk cannot be rejected for the Canadian-U.S. Dollar rate. Other notable currencies include the Australian dollar and the Euro, both of which seem to exhibit random price behavior.

We also fail to reject the random walk hypothesis for the S\&P 500, a value-weighted index, at any conventional lag. Similarly, we cannot reject the random walk hypothesis for many other major international equity markets, including China, the United Kingdom, France, Germany, India, Brazil, Switzerland, South Korea, Spain, and Sweden. This is consistent with the findings of Campbell, Lo and MacKinlay (1997). ${ }^{4}$ They cannot reject the random walk hypothesis for a U.S. valueweighted index. However, the main finding of their paper is that they reject the random walk for the CRSP equal-weighted index. Accordingly, they suggest that firm size is a driving factor for the "randomness" of its security price. From our analysis, it appears that risk-adjusted returns are also an indicator of predictability. For example, by ordering markets according to their Sharpe ratios ${ }^{5}$, $S=\frac{\mu}{\sigma}$, we notice that the seven weakest equity markets in our sample: Czech Republic, Philippines, Japan, Thailand, Italy, and Argentina, all reject the random walk. This result is supported by economic intuition. Low risk-adjusted returns should decrease the demand for analyst coverage, which would result in weaker informational efficiency.

\footnotetext{
${ }^{4}$ The Campbell, Lo, and MacKinlay (1997) findings are based on U.S. value-weighted index data from the Center for Research in Security Prices (CRSP) dated July 10, 1962 to December 27, 1994.

${ }^{5}$ The conventional form of the Sharpe ratio is $S=\frac{\mu-r_{f}}{\sigma}$, where $r_{f}$ is the risk-free rate. Because of the scarcity and inconsistency of data on international risk-free interest rates, and given our use of local currency-denominated equity indices, we ignore this term. Thus, the Sharpe Ratio, as defined in this paper, is simply $S=\frac{\mu}{\sigma}$.
} 
In Figure 2.2.1, we show a scatterplot of the Sharpe ratio $(S)$ against the maximum value over all lags of the absolute value of $z^{*}(q)$. The $S$ was calculated using the return and standard deviation of returns over all available data. Sweden was immediately disregarded as an outlier.

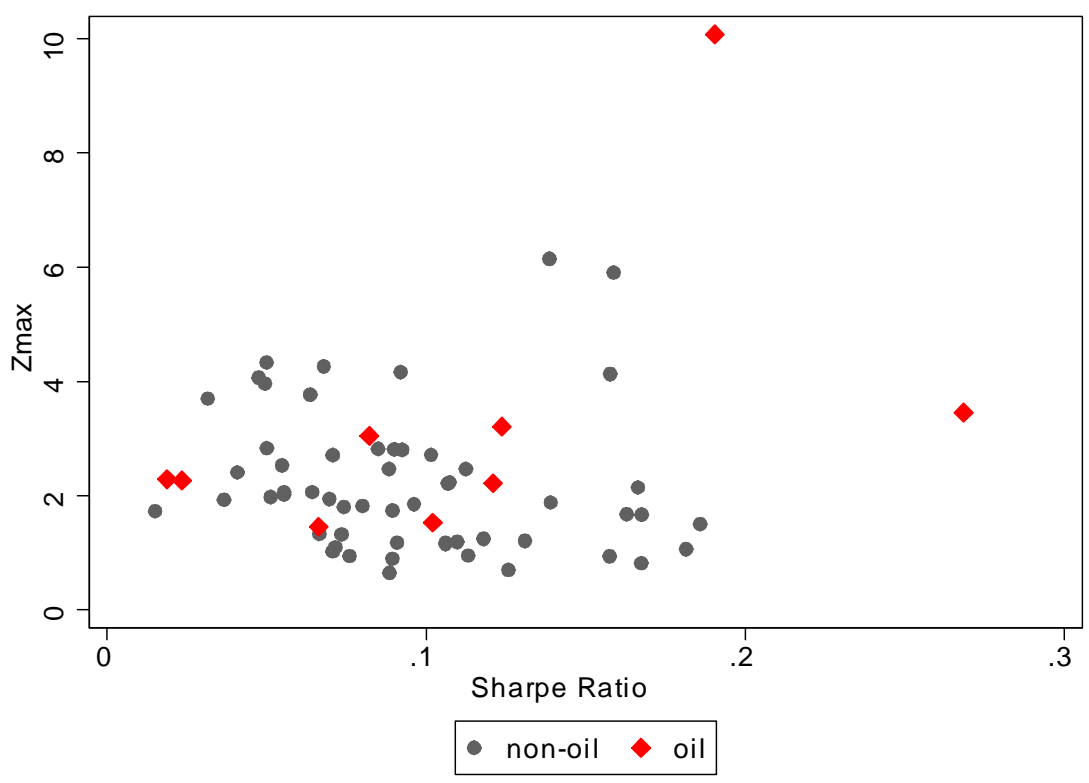

Figure 2.2.1

We immediately noticed that energy commodities and OPEC-member equity markets tended to deviate from the majority of the data. Removing these points magnifies the relationship between risk-adjusted performance and forecastability, as shown in Figure 2.2.2. 


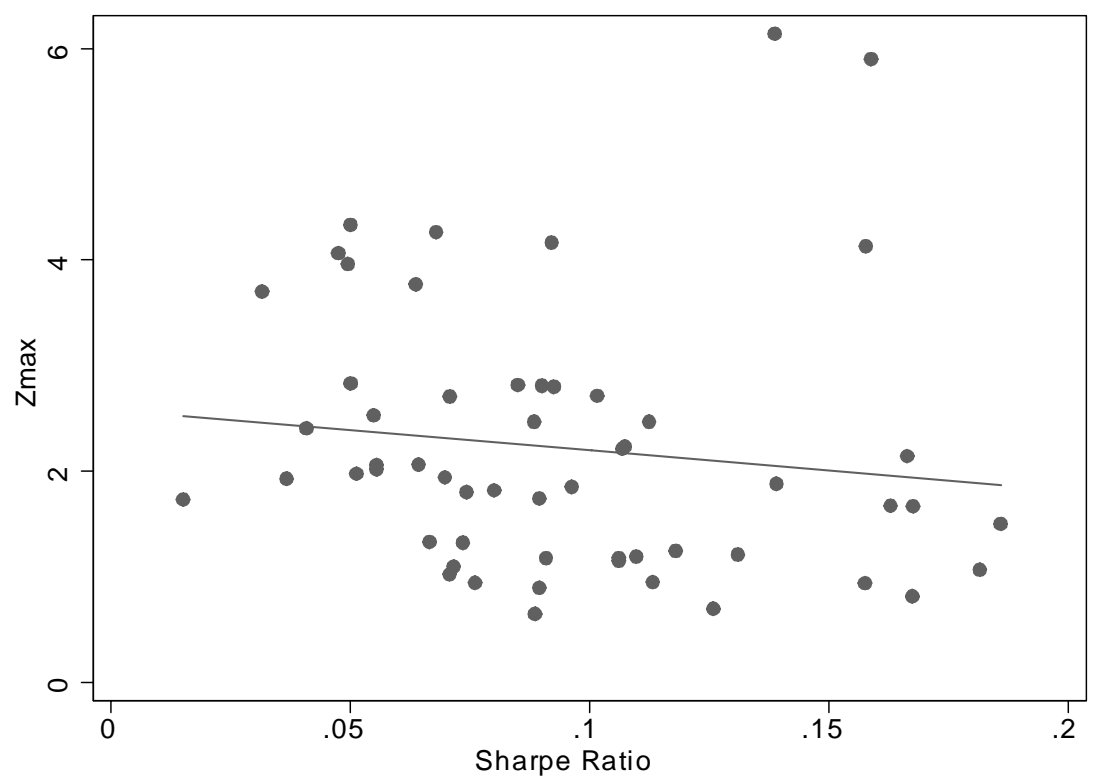

Figure 2.2.2

Table 2.2.1 shows the correlation between these series along with the coefficients and t-statistics of a regression of a dummy variable which indicates whether or not that market can reject the random walk with $95 \%$ confidence at some lag (i.e. $\left.\max \left(\left|z^{*}(q)\right|\right)>1.96\right)$ on the $S$. Though only the OLS estimates are reported, the results are robust to several modifications, including robust standard errors and iteratively reweighted least squares with Huber and biweight functions tuned to $95 \%$ efficiency.

\begin{tabular}{|l|c|c|c|}
\hline \multicolumn{4}{|c|}{ Table 2.2 .1} \\
\hline Assets & $\begin{array}{c}\text { Correlation } \\
\left(S, \max \left(\left|z^{*}(q)\right|\right)\right)\end{array}$ & $\boldsymbol{\beta}$ & t-stat \\
Non-Oil & -0.13 & -3.25 & -2.05 \\
\hline
\end{tabular}

This preliminary evidence supports our hypothesis that there exists a positive relationship between risk-adjusted market performance and efficiency. Further research in this area would likely prove rewarding.

\subsection{Power}

In this section, we detail the relative power of the Lo and MacKinlay (1988) heteroscedasticityconsistent random walk test compared to the more restrictive random walk under homoscedastic 
increments. One should expect that, for random asset price innovations, both the homoscedastic and heteroscedastic methodologies will fail to reject the null hypothesis of a random walk and produce very similar results. Our simulation results confirm this. As an example, we include the first sample of the simulation in Figure 2.3.1.

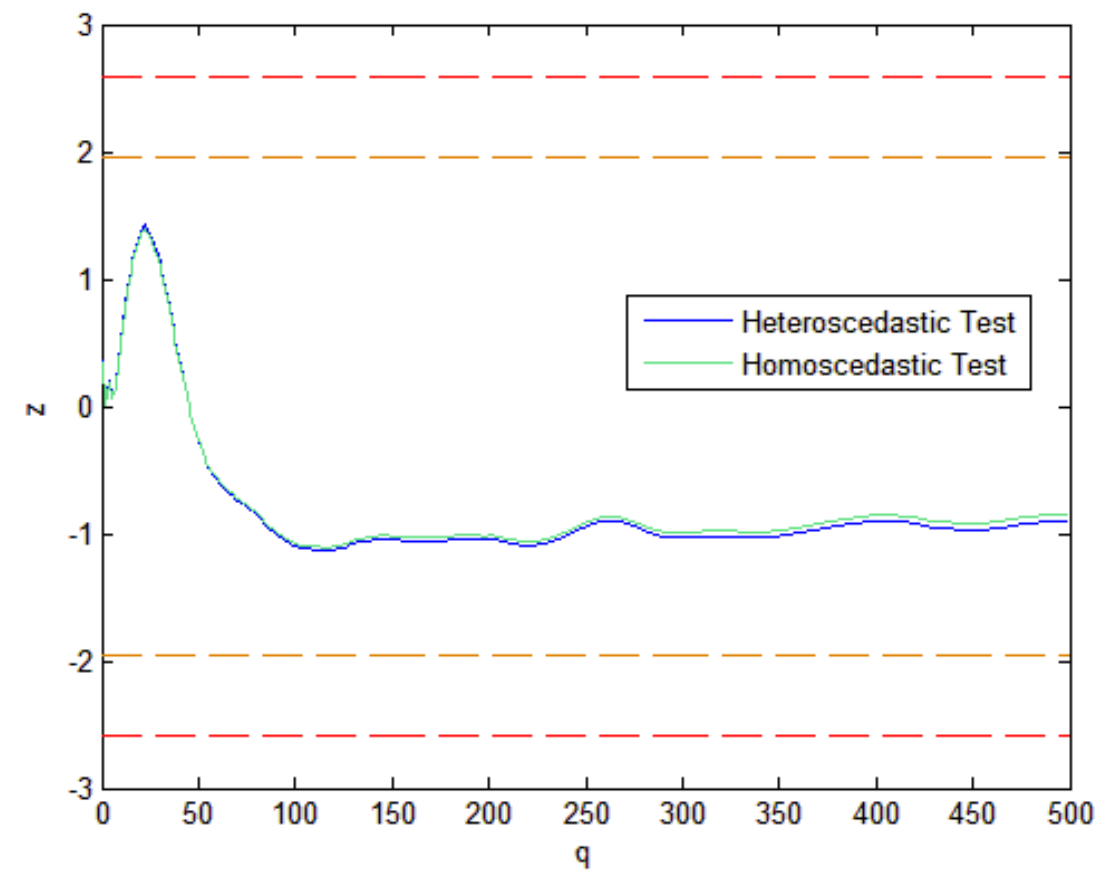

Figure 2.3.1: IID-Normal Process

It is less obvious how the random walk tests will behave in the presence of time-varying volatility. Under $\operatorname{GARCH}(1,1)$ processes, the heteroscedasticity-consistent random walk test employed in this paper is shown to be robust to time-varying volatility and appropriately fails to reject the random walk, whereas the homoscedastic alternative is biased towards rejection. Figure 2.3.2 shows the first sample in our simulation and the rejection bias of the homoscedastic test. 


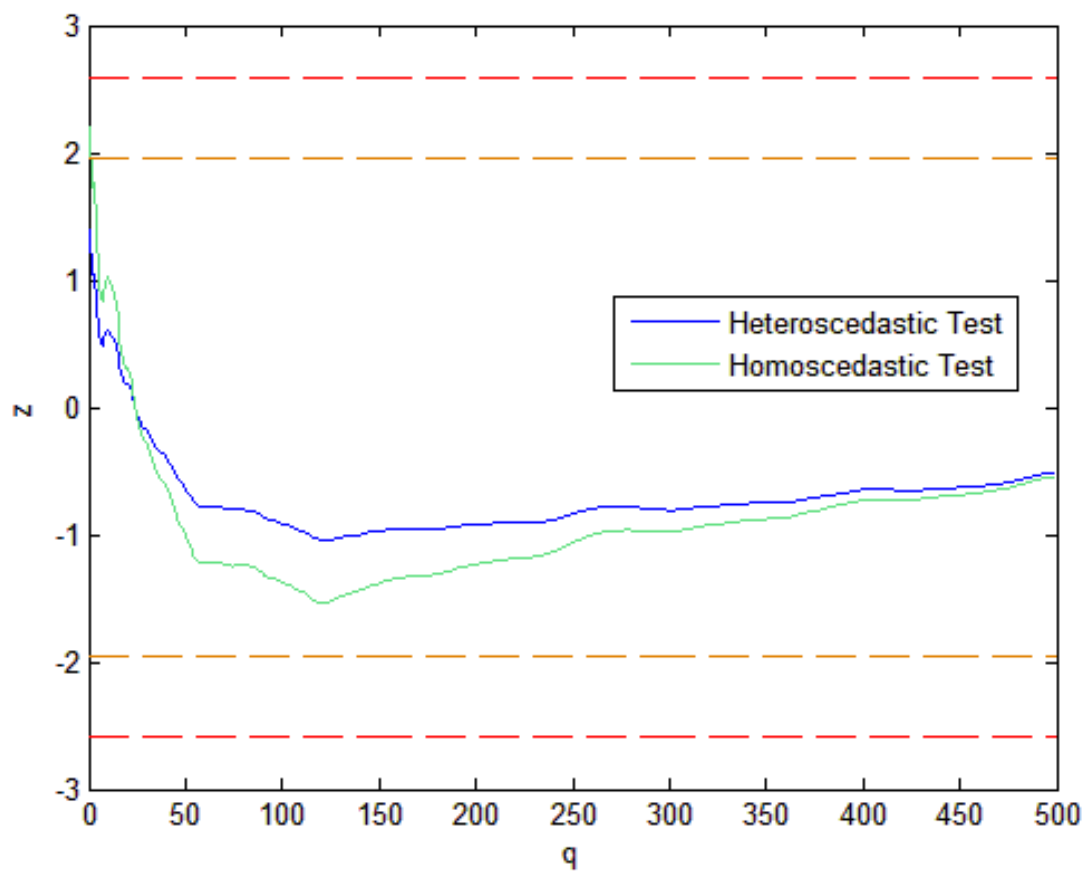

Figure 2.3.2: $\operatorname{GARCH}(1,1)$ Process

More formally, we use Monte Carlo simulations to generate 10,000 GARCH(1,1) processes $^{6}$ for $X_{t}$, of the size $n=1000$, and then apply the homoscedastic and heteroscedastic random walk tests to the data. The results for several arbitrary lags, $q$, are presented in Table 2.3.1.

\begin{tabular}{|c|l|cccccc|}
\hline \multicolumn{7}{|c|}{ Table 2.3.1: Percent of GARCH(1,1) Processes Rejected } \\
\hline $\begin{array}{c}\text { Confidence } \\
\text { Level }(\varphi)\end{array}$ & Methodology & 2 & 4 & 8 & 16 & 32 & 64 \\
\hline \hline \multirow{2}{*}{$\varphi=95 \%$} & Homoscedastic & 12.41 & 12.35 & 11.57 & 11.08 & 9.85 & 8.12 \\
& Heteroscedastic & 5.04 & 5.28 & 5.30 & 4.71 & 4.88 & 4.88 \\
\hline \multirow{2}{*}{$\varphi=99 \%$} & Homoscedastic & 4.39 & 4.63 & 4.42 & 4.12 & 3.38 & 3.53 \\
& Heteroscedastic & 0.83 & 1.07 & 1.35 & 1.41 & 1.58 & 2.03 \\
\hline
\end{tabular}

The above table clearly shows that the homoscedastic test is biased towards rejection in the presence of time-varying volatility. This evidence supports our use of the heteroscedasticity-consistent test because it is the forecastability of price changes that is of primary interest in random walk analysis.

\footnotetext{
${ }^{6} \mathrm{GARCH}$ processes are written of the form $\operatorname{GARCH}(v, w)$, where $v$ is the number of lags of the conditional variance and $w$ is the number of lags of the squared innovations. For simplicity, we assume the common $\operatorname{GARCH}(1,1)$ process and then estimate the GARCH coefficients from our weekly S\&P 500 data.
} 


\section{Long Memory}

Because a new type of test is needed for long memory analysis, we surveyed the literature for alternatives. Although powerful for theoretical modeling and volatility analysis, studies based upon the absolute value of returns (i.e. Ding, Granger, and Engle 1993; and Dacorogna et. al 1993) provide no intuition regarding the direction of a long memory cycle, only its existence. The rescaled range class of test statistics, however, are able to distinguish between positive strong dependence (persistence) and negative strong dependence (mean reversion).

\subsection{Methodology}

Again we denote $P_{t}$ as the index level at time $t$ and define the continuously compounded single period return from $t-1$ to $t$ as $X_{t} \equiv \ln P_{t}-\ln P_{t-1}$. To avoid confusion with the notation from our random walk test in section 2, we denote the truncation lag, in days, as $\xi$. Our long memory methodology follows exactly from Lo (1991).

\subsubsection{Classical Hurst-Mandelbrot Rescaled Range}

The classical Hurst-Mandelbrot rescaled range statistic is

$$
\tilde{Q}_{n} \equiv \frac{1}{s_{n}}\left[\operatorname{Max}_{1 \leq k \leq n} \sum_{j=1}^{k}\left(X_{j}-\bar{X}_{n}\right)-\operatorname{Min}_{1 \leq k \leq n} \sum_{j=1}^{k}\left(X_{j}-\bar{X}_{n}\right)\right],
$$

where $s_{n}$ is the usual maximum likelihood standard deviation estimator

$$
s_{n} \equiv\left[\frac{1}{n} \sum_{j=1}^{n}\left(X_{j}-\bar{X}_{n}\right)^{2}\right]^{1 / 2} .
$$

When properly normalized, this statistic weakly converges to the range of the Brownian bridge.

$$
\tilde{V}_{n} \Longleftarrow \frac{1}{\sqrt{n}} \tilde{Q}_{n}
$$

The classical rescaled range statistic, however, does not distinguish between short- and long-term dependence. Lo (1991) shows that for short-term autocorrelation coefficients, $\hat{\rho}$, of 50 percent, the mean of $\tilde{V}_{n}$ may be biased upward by 73 percent, causing a rejection of the null hypothesis at any conventional significance level. Given this weakness and the short-term autoregressive properties of our data described in section 2.2 , we selected the modified rescaled range statistic $($ Lo, 1991) for our long memory analysis because of its invariance to short-term serial correlation. 


\subsubsection{Lo's Modified Rescaled Range}

The modified rescaled range statistic differs only in its denominator to achieve invariance to short memory processes:

$$
Q_{n} \equiv \frac{1}{\hat{\sigma}_{n}(\xi)}\left[\operatorname{Max}_{1 \leq k \leq n} \sum_{j=1}^{k}\left(X_{j}-\bar{X}_{n}\right)-\operatorname{Min}_{1 \leq k \leq n} \sum_{j=1}^{k}\left(X_{j}-\bar{X}_{n}\right)\right]
$$

where

$$
\begin{gathered}
\hat{\sigma}_{n}^{2}(\xi) \equiv \frac{1}{n} \sum_{j=1}^{n}\left(X_{j}-\bar{X}_{n}\right)^{2}+\frac{2}{n} \sum_{j=1}^{\xi} \omega_{j}(\xi)\left[\sum_{i=j+1}^{n}\left(X_{i}-\bar{X}_{n}\right)\left(X_{i-j}-\bar{X}_{n}\right)\right] \\
=\hat{\sigma}_{x}^{2}+2 \sum_{j=1}^{\xi} \omega_{j}(\xi) \hat{\gamma}_{j}, \quad \omega_{j}(\xi) \equiv 1-\frac{j}{\xi+1}, \quad \xi<n,
\end{gathered}
$$

and $\hat{\sigma}_{x}^{2}$ and $\hat{\gamma}_{j}$ are the sample variance and autocovariance up to lag $\xi$ of $X$, respectively. Note that the modified rescaled range simplifies to the classical Hurst-Mandelbrot rescaled range statistic in the special case where $\xi=0$.

A main criticism of the modified $\mathrm{R} / \mathrm{S}$ is that there is little guidance about how to select an optimal truncation lag, $\xi$. If $\xi$ is chosen too small, significant autocovariances may be ignored, thus biasing the $Q_{n}$ statistic. Also, if $\xi$ is too large relative to the sample size, Lo and MacKinlay (1989) show that the finite-sample distribution deviates significantly from its asymptotic limit.

Andrews (1991) provides an asymptotic data-dependent $\xi^{*}$

$$
\xi^{*}=\left[k_{n}\right], \quad k_{n} \equiv\left(\frac{3 n}{2}\right)^{\frac{1}{3}} \cdot\left(\frac{2 \hat{\rho}}{1-\hat{\rho}^{2}}\right)^{\frac{2}{3}}
$$

where $\left[k_{n}\right]$ is the greatest integer less than or equal to $k_{n}$, and $\hat{\rho}$ is the first-order autocorrelation coefficient. We show the Andrews (1991) data dependent $\xi^{*}$ in section 3.2 below; a broader range of $\xi$ 's are graphed in Appendix 4. Although we report the Andrews $\xi^{*}$ in this paper, it has not been proven to be an optimal method for selecting $\xi$, and no known method currently exists.

In determining the significance of our results, it can be shown that the modified rescaled range statistic converges to the range of the Brownian bridge

$$
\frac{1}{\sqrt{n}} Q_{n} \Longrightarrow V_{n}(\xi)
$$

Following from Theorem 3.1 of Lo (1991), the cumulative distribution function (CDF) for the 
range of the Brownian bridge is given as

$$
F_{V}(v)=1+2 \sum_{k=1}^{\infty}\left(1-4 k^{2} v^{2}\right) e^{-2(k v)^{2}} .
$$

Critical values of the two-tailed test can be obtained from the above equation; the most commonly used values are shown in Table 3.1.2.1.

Table 3.1.2.1: Critical Values of the Distribution $F_{V}(v)$

\begin{tabular}{cccccccc}
\hline$P(V<v)$ & 0.005 & 0.025 & 0.050 & 0.500 & 0.950 & 0.975 & 0.995 \\
\hline$v$ & 0.721 & 0.809 & 0.861 & 1.223 & 1.747 & 1.862 & 2.098 \\
\hline
\end{tabular}

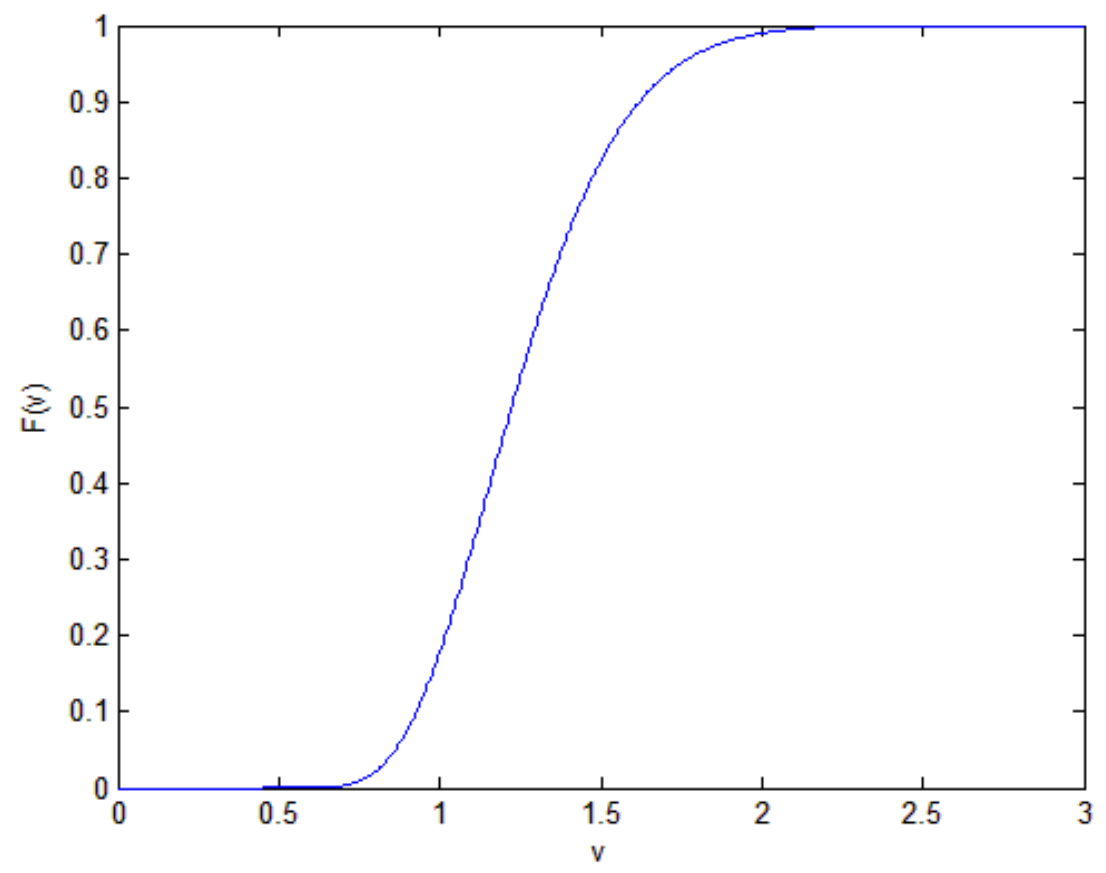

Figure 3.1.2.1: Cumulative Distribution Function of the Modified R/S

\subsection{Results}

The results of our long memory analysis are shown in detail in Appendix 4. Again, the dashed orange and red lines represent 95 and 99 percent rejection levels of the modified rescaled range hypothesis test, respectively. Significantly large $V$-values indicate positive strong dependence. $V$-values below the lower rejection band show negative strong dependence. Table 3.2.1 reports numerical re- 
sults of our modified rescaled analysis using Andrews' (1991) data-dependent $\xi^{*} .^{7}$

We find little evidence for long-term memory in global equity indices. With adjustments for short-term autocorrelations of up to 250 trading days, approximately one year, the null hypothesis of no long term dependence cannot be rejected ${ }^{8}$ for 36 of the 44 equity markets studied. Criticisms levied against the modified rescaled range by Baillie (1996), for example, cite that

...a major practical difficulty concerns the choice of $q[\xi]$ and how to distinguish between short range dependencies and long range dependencies.

Our graphical results in Appendix 4 do not support this claim. We fail to reject the null hypothesis at every integer lag for the United States, United Kingdom and many other emerging and industrialized equity markets. Furthermore, our findings are largely consistent with other analyses of the U.S. (Lo, 1991) and global (Chow et. al, 1996) equity markets.

In the foreign exchange markets, we find great disparity in the long memory evidence between emerging and industrialized economies. Contrary to Mulligan (2000), ${ }^{9}$ we find no evidence of long memory in the bilateral trade of U.S. dollars with other advanced market currencies. A likely reason for this disparity is Mulligan's use of monthly averages instead of point data, which may bias results in the presence of short-term dependece in the daily data. We reject the null hypothesis for many emerging economies, however, particularly in Latin America.

We find very little evidence of long memory in most commodity markets. However, Corrazza et. al. (1997) found fractal returns in the futures markets for soybeans, wheat, oats, and corn. We similarly found long memory in the spot returns of the soybeans market.

\footnotetext{
${ }^{7}$ As in Lo (1991), when reporting results for the data-dependent $\xi^{*}$, we replace the Newey and West (1987) autocorrelation weights, $\omega_{j}(\xi)$, in equation (14) with those suggested by Andrews (1991): $\omega_{j}=1-\left|\frac{j}{k_{n}}\right|$.

${ }^{8} \mathrm{~A}$ rejection of the null hypothesis does not precisely imply that long memory is present, but that the stochastic process does not simultaneously satisfy all of the hypothesis conditions in Lo (1991).

${ }^{9}$ Mulligan (2000) uses monthly data from the Federal Reserve Bank of St. Louis.
} 


\begin{tabular}{|c|c|c|c|c|c|c|c|}
\hline \multirow[b]{2}{*}{ Country } & \multicolumn{2}{|c|}{ Equity Indices } & \multicolumn{2}{|c|}{ Foreign Exchange } & \multirow[b]{2}{*}{ Commodity } & \multirow[b]{2}{*}{$\xi^{*}$} & \multirow[b]{2}{*}{$\mathrm{V}\left(\xi^{*}\right)$} \\
\hline & $\xi^{*}$ & $\mathrm{~V}\left(\xi^{*}\right)$ & $\xi^{*}$ & $\mathrm{~V}\left(\xi^{*}\right)$ & & & \\
\hline Argentina & 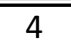 & 1.50 & 2 & $1.91^{*}$ & Crude Oil & 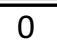 & 0.95 \\
\hline Brazil & 5 & 1.31 & 3 & $1.89 *$ & Gasoline & 1 & 1.06 \\
\hline Chile & 14 & 1.75 & 3 & $1.88^{*}$ & Natural Gas & 0 & 0.92 \\
\hline Colombia & 7 & 1.62 & 0 & $1.91^{*}$ & Heating Oil & 3 & 1.02 \\
\hline Mexico & 7 & 1.38 & 0 & 1.00 & Copper & 4 & 1.28 \\
\hline Peru & 11 & $2.31 * *$ & 2 & 1.41 & Aluminum & 2 & 1.26 \\
\hline Venezuela & 8 & 1.25 & --- & --- & Lead & 4 & 1.26 \\
\hline China & 2 & 1.38 & --- & --- & Nickel & 1 & 1.30 \\
\hline Hong Kong & 4 & 1.37 & --- & --- & Tin & 4 & 1.54 \\
\hline Indonesia & 12 & 1.66 & 6 & 1.46 & Zinc & 0 & 1.47 \\
\hline India & 6 & 1.45 & 9 & $2.12^{* *}$ & Gold & 3 & 1.03 \\
\hline South Korea & 6 & $1.88^{*}$ & 7 & $1.95^{*}$ & Platinum & 2 & 1.39 \\
\hline Malaysia & 8 & 1.50 & 1 & 1.35 & Silver & 2 & 1.00 \\
\hline Philippines & 9 & 1.37 & 5 & 1.67 & Cotton & 2 & 1.58 \\
\hline Russia & 7 & 1.66 & 8 & $2.00^{*}$ & Rubber & 13 & 1.21 \\
\hline Singapore & 9 & 1.48 & 5 & 1.34 & Corn & 0 & 1.65 \\
\hline Taiwan & 5 & 1.50 & --- & --- & Wheat & 5 & 1.19 \\
\hline Thailand & 7 & 1.79 & 4 & 1.57 & Soybeans & 1 & $2.08^{*}$ \\
\hline Israel & 1 & 0.98 & 2 & $2.05^{*}$ & Cattle & 2 & $0.72 * *$ \\
\hline Kuwait & 1 & 1.85 & --- & --- & Cocoa & 2 & 0.90 \\
\hline Nigeria & 15 & 1.21 & 12 & 1.23 & Coffee & 0 & 1.25 \\
\hline Saudi Arabia & 2 & $2.20 * *$ & --- & --- & Sugar & 4 & 1.57 \\
\hline South Africa & 4 & 1.43 & 1 & $2.01^{*}$ & & & \\
\hline Turkey & 4 & 1.47 & 5 & 1.36 & & & \\
\hline UAE & 2 & $2.16^{* *}$ & --- & --- & & & \\
\hline Australia & 7 & 1.36 & 3 & 1.30 & & & \\
\hline Belgium & 8 & 1.85 & --- & --- & & & \\
\hline Canada & 9 & 0.99 & 2 & 1.64 & & & \\
\hline Czech Republic & 5 & 1.86 & 1 & 1.71 & & & \\
\hline Denmark & 3 & $2.02^{*}$ & --- & --- & & & \\
\hline European Union & --- & --- & 0 & 1.51 & & & \\
\hline France & 2 & 1.54 & --- & --- & & & \\
\hline Germany & 1 & 1.58 & --- & --- & & & \\
\hline Hungary & 5 & 1.39 & --- & --- & & & \\
\hline Italy & 11 & 1.61 & --- & --- & & & \\
\hline Japan & 7 & $1.95^{*}$ & 3 & 1.23 & & & \\
\hline Netherlands & 0 & 1.40 & --- & --- & & & \\
\hline Norway & 1 & $2.12^{* *}$ & 0 & 1.43 & & & \\
\hline New Zealand & 5 & 1.00 & 2 & 1.45 & & & \\
\hline Poland & 6 & 1.32 & 3 & 1.79 & & & \\
\hline Sweden & 1 & $1.93 *$ & 0 & 1.48 & & & \\
\hline Spain & 2 & 1.63 & --- & --- & & & \\
\hline Switzerland & 2 & 1.48 & 2 & 1.38 & & & \\
\hline UK & 2 & 1.18 & 4 & 1.44 & & & \\
\hline US & 5 & 1.57 & --- & --- & & & \\
\hline
\end{tabular}

* and $* *$ denote significance at the 95 and 99 percent confidence levels, respectively

Table 3.2.1: Results of the Modified R/S Test for Optimal Lag, $\xi^{*}$ 


\section{Conclusion}

This paper presents an extensive analysis of short- and long-term memory in the returns of international financial data. The random walk section attempts to answer the question, can asset prices be forecasted based on historical price information alone? Using a heteroscedasticity-consistent test, we conclude that financial data are broadly unpredictable with a few notable exceptions. First, energy prices exhibit mean-reverting price behavior. Second, markets with poorer risk-adjusted performance are more likely the reject the random walk. We expect that prolonged, weak performance in these markets has deterred analyst coverage, resulting in relatively low informational efficiency. This idea is consistent with contrarian investment strategies which seek to earn positive abnormal returns in depressed markets.

Much of the empirical literature on long memory concerns the rate of decay in the autocorrelation of volatility. Although important for applications in risk management, options and other derivative markets, long memory in volatility does not provide intuition regarding the direction of the cycle in returns. When Hurst (1951) set out to identify long memory patterns in the Nile River, for example, he was not concerned with identifying volatility in sediment discharge, but the prediction of flood (positive) and drought (negative) cycles to improve river management in the delta. We are concerned with similar questions in asset pricing. Can we identify long term cycles in asset prices to earn excess returns? We attempt to answer this question via a modernization of Hurst's test, the modified rescaled range statistic, and, in financial asset returns, we find very little evidence of long memory cycles. The most promising area for further long memory research appears to be the bilateral exchange of U.S. dollars with the currencies of Latin American economies. 


\section{References}

[1] Andrews, D. (1991), Heteroskedasticity and Autocorrelation Consistent Covariance Matrix Estimation, Econometrica 59, 817-858.

[2] Baillie, R. T. (1996), Long Memory Processes and Fractional Integration in Econometrics, Journal of Econometrics 73, 5-59.

[3] Baillie, R. T., Bollerslev, T., and Mikkelsen, H. O. (1996), Fractionally Integrated Generalized Autoregressive Conditional Heteroskedasticity, Journal of Econometrics 74, 3-30.

[4] Bleaney, M., and Greenaway, D. (1993), Long-Run Trends in the Relative Price of Primary Commodities and in the Terms of Trade of Developing Countries, Oxford Economic Papers 45, 349-363.

[5] Bollerslev, T., (1986), Generalized Autoregressive Conditional Heteroskedasticity, Journal of Econometrics 31, 307-327.

[6] Calvet, L., Fisher, A., and Mandelbrot, B. B. (1997), A Multifractal Model of Asset Returns, Cowles Foundation Discussion Papers, 1164.

[7] Campbell, J. Y., Lo, A. W., and MacKinlay, C. (1997), The Econometrics of Financial Markets, New Jersery: Princeton University Press.

[8] Canarella, G., and Pollard, S. K. (1985), Efficiency of Commodity Futures: A Vector Autoregression Analysis, The Journal of Futures Markets 5, 57-76.

[9] Chow, K. V., Pan, M., and Sakano, R. (1996), On the Long-Term or Short-Term Dependence in Stock Prices: Evidence from International Stock Markets, Review of Quantitative Finance and Accounting 6, 181-194.

[10] Corazza, M., Malliaris, G., Nardelli, C., 1997. Searching for fractal structure in agricultural futures markets. Journal of Futures Markets, 17, 433-473.

[11] Dacorogna, M. M., Müller, U. A., Nagler, R. J., Olsen, R. B., and Pictet, O. V. (1993), A Geographical Model for the Daily and Weekly Seasonal Volatility in the Foreign Exchange Market, Journal of International Money and Finance 12, 413-438.

[12] Dickey, D. A. and Fuller, W. A. (1979), Autoregressive Time Series with a Unit Root, Journal of the American Statistical Association 74, 427-431. 
[13] Ding, Z., Granger, C. W. J., and Engle, R. F. (1993), A Long Memory Property of Stock Returns and a New Model, Journal of Empirical Finance 1, 83-106.

[14] Engle, R. F. (1982), Autoregressive Conditional Heteroscedasticity with Estimates of the Variance of United Kingdom Inflation, Econometrica, 50, 987-1007.

[15] Geman, H. (2007), Mean Reversion versus Random Walk in Oil and Natural Gas Prices, Advances in Mathematical Finance, Birkhauser Boston.

[16] Hurst, H. E. (1951), Long-term Storage Capacity of Reservoirs, Transactions of the American Society of Civil Engineers 116, 770-799.

[17] International Monetary Fund (2006), Annual Report on Exchange Arrangements and Exchange Restrictions, 2006.

[18] Liu, C. Y., and He, J. (1991), A Variance-Ratio Test of Random Walks in Foreign Exchange Rates, Journal of Finance 46, 773-785.

[19] Lo, A. W. (1991), Long Term Memory in Stock Market Prices, Econometrica 59, 1279-1313.

[20] Lo, A. W., and MacKinlay, C. (1988), Stock Market Prices Do Not Follow Random Walks: Evidence from a Simple Specification Test, Review of Financial Studies 1, 41-66.

[21] Lo, A. W., and MacKinlay, C. (1989), The Size and Power of the Variance Ratio Test in Finite Samples: A Monte Carlo Investigation, Journal of Econometrics 40, 203-238.

[22] Malkiel, B. G. (1973), A Random Walk Down Wall Street, New York: W. W. Norton and Company.

[23] Mandelbrot, B. B. (1963), The Variation of Certain Speculative Prices, Journal of Business 36, 394-419.

[24] Mandelbrot, B. B. (1971), When Can Price be Arbitraged Efficiently? A Limit to the Validity of the Random Walk and Martingale Models, Review of Economics and Statistics 53, 225-236.

[25] Mandelbrot, B. B. (1972), Statistical Methodology for Nonperiodic Cycles: From the Covariance to R/S Analysis, Annals of Economic and Social Measurement 1/3, 259-290.

[26] Mulligan, R. F. (2000), A Fractal Analysis of Foreign Exchange Markets, International Advances in Economic Research 6, 33-49. 
[27] Newey, W. K., and West, K. D. (1987), A Simple Positive Definite, Heteroscedasticity and Autocorrelation Consistent Covariance Matrix, Econometrica 55, 703-708.

[28] Roberts, H. (1967), Statistical versus Clinical Prediction of the Stock Market, Center for Research in Security Prices, University of Chicago.

[29] Sharpe, W. F. (1991), The Arithmetic of Active Management, Financial Analysts Journal 47, 7-9.

[30] Taylor, S. (1986), Modelling Financial Time Series, New York: Wiley. 


\section{Appendix 1 Data}

\section{Appendix 1.1 Equity Indices}

Daily equity index data for each country were downloaded from Bloomberg. We downloaded the fields "px_last" (last price) and "eqy_last_dps_gross" (dividends per share) to create a total return series according to the fundamental relationship:

$$
\begin{gathered}
P_{1}=\alpha_{1} \\
P_{t}=P_{t-1}\left[\left(\frac{\varphi_{t}}{\alpha_{t-1}}\right)+\left(\frac{\alpha_{t}}{\alpha_{t-1}}\right)\right] .
\end{gathered}
$$

We initialized the first observation of the total return index, $P_{1}$, to equal the basic index level, $\alpha_{1}$. Equation 19 was then used to construct the total return index series as the sum of the dividend and capital gains yields, respectively, where $\varphi_{t}$ are dividends per share. Because our Bloomberg download program only provided two decimal places, and indices are calculated with an arbitrary base (i.e. $1995=100$ ), time series of countries experiencing extraordinary growth or crises were truncated to avoid rounding errors. For example, at the beginning of the dataset, some countries (like Peru), had index values at or near "0.00". Returns calculated on such low price levels were inherently undefined or extremely volatile, and thus not representative of the historical record. As a rule-of-thumb, we corrected for this by eliminating the first $t$ observations where $\alpha_{t}<100$, leaving a residual rounding error no greater than $\frac{\alpha_{t}}{20000}$.

\begin{tabular}{llll} 
Country & Ticker & Description & Sample (mm/dd/yy) \\
\hline \hline Latin America & & & \\
$($ AR) Argentina & MAR & Merval Index & $01 / 03 / 00-03 / 07 / 08$ \\
$(B Z)$ Brazil & IBX & IBX Index & $01 / 02 / 99-03 / 07 / 08$ \\
$(\mathrm{CL})$ Chile & IGPA & IPSA Stock Index & $01 / 03 / 90-03 / 07 / 08$ \\
$(\mathrm{CO})$ Colombia & IGBC & IGBC Stock Index & $07 / 04 / 01-03 / 07 / 08$ \\
$(\mathrm{MX})$ Mexico & MEXBOL & Bolsa Stock Index & $01 / 03 / 89-03 / 07 / 08$ \\
$(\mathrm{PE})$ Peru & IGBVL & Peru Lima General Index & $01 / 03 / 92-03 / 07 / 08$ \\
$(\mathrm{VE})$ Venezuela & IBVC & IBC Stock Index & $01 / 03 / 94-03 / 07 / 08$
\end{tabular}

Emerging Asia

(CH) China

SHCOMP Shanghai Composite Index

$01 / 04 / 95-03 / 07 / 08$

(HK) Hong Kong

HSI

Hang Seng Stock Index

$11 / 25 / 69$ - 03/07/08 


\begin{tabular}{|c|c|c|c|}
\hline Country & Ticker & Description & Sample (mm/dd/yy) \\
\hline (ID) Indonesia & JCI & Jakarta Stock Index & $04 / 05 / 83-03 / 07 / 08$ \\
\hline (IN) India & SENSEX & Sensex Stock Index & $04 / 04 / 79-03 / 07 / 08$ \\
\hline (KO) South Korea & KOSPI & KOSPI Stock Index & $01 / 05 / 80-03 / 07 / 08$ \\
\hline (MA) Malaysia & KLCI & Kuala Lumpur Composite & $01 / 04 / 77-03 / 07 / 08$ \\
\hline (PH) Philippines & PCOMP & PSEI Stock Index & $01 / 05 / 87-03 / 07 / 08$ \\
\hline (RU) Russia & RTSI\$ & Russian Trading System & $09 / 04 / 95-03 / 07 / 08$ \\
\hline (SI) Singapore & SESALL & All-Equities Stock Index & $01 / 03 / 75-03 / 07 / 08$ \\
\hline (TA) Taiwan & TWSE & TWSE Stock Index & $01 / 05 / 73-03 / 07 / 08$ \\
\hline (TH) Thailand & SET & Bangkok SET Stock Index & $07 / 03 / 87-03 / 07 / 08$ \\
\hline \multicolumn{4}{|c|}{ Middle East and Africa } \\
\hline (IS) Israel & TA-25 & Tel Aviv 25 Stock Index & $01 / 05 / 92-03 / 07 / 08$ \\
\hline (KW) Kuwait & KWSEIDX & Kuwait SE Unweighed Index & $06 / 18 / 01-03 / 07 / 08$ \\
\hline (NG) Nigeria & NGSEINDX & Nigeria Stock Exchange & $01 / 05 / 98-03 / 07 / 08$ \\
\hline (SA) Saudi Arabia & SASEIDX & Tadawul All-Shares & $01 / 29 / 94-03 / 07 / 08$ \\
\hline (SF) South Africa & JALSH & JSE All-Shares Stock Index & $07 / 03 / 95-03 / 07 / 08$ \\
\hline (TK) Turkey & XU100 & Istanbul National 100 Index & $01 / 03 / 90-03 / 07 / 08$ \\
\hline (UA) UAE & DFMGI & Dubai General Stock Index & $01 / 03 / 04-03 / 07 / 08$ \\
\hline \multicolumn{4}{|c|}{ Industrialized Economies } \\
\hline (AL) Australia & AS30 & All Ordinaries Stock Index & $01 / 02 / 80-03 / 07 / 08$ \\
\hline (BE) Belgium & BELSTK & Belgian All-Shares & $10 / 04 / 88-03 / 07 / 08$ \\
\hline (CA) Canada & SPTSX & S\&P Toronto Stock Index & $01 / 04 / 77-03 / 07 / 08$ \\
\hline (CZ) Czech Republic & PX & PX Stock Index & $09 / 20 / 94-03 / 07 / 08$ \\
\hline (DN) Denmark & KAX & OMX Copenhagen & $01 / 02 / 96-03 / 07 / 08$ \\
\hline (FR) France & SBF250 & SBF 250 Stock Index & $01 / 02 / 91-03 / 07 / 08$ \\
\hline (GE) Germany & HDAX & HDAX Stock Index & $01 / 04 / 88-03 / 07 / 08$ \\
\hline (HU) Hungary & BUX & Budapest Stock Exchange & $01 / 03 / 91-03 / 07 / 08$ \\
\hline (IT) Italy & ITSMBANC & Bacchi Stock Index & $01 / 03 / 73-03 / 07 / 08$ \\
\hline (JA) Japan & TPX & TOPIX Stock Index & $01 / 06 / 70-03 / 07 / 08$ \\
\hline (NE) Netherlands & AEX & Amsterdam Exchanges Index & $01 / 04 / 83-03 / 07 / 08$ \\
\hline (NO) Norway & OSEAX & Oslo All-Shares Stock Index & $01 / 02 / 96-03 / 07 / 08$ \\
\hline (NZ) New Zealand & NZSE & All Ordinaries Stock Index & $03 / 31 / 92-03 / 07 / 08$ \\
\hline
\end{tabular}




\begin{tabular}{llll} 
Country & Ticker & Description & Sample (mm/dd/yy) \\
\hline \hline (PL) Poland & WIG & WSE WIG Index & $04 / 23 / 91-03 / 07 / 08$ \\
(SD) Sweden & SWSMAFFR & Affarsvarlden Stock Index & $01 / 04 / 00-03 / 07 / 08$ \\
(SP) Spain & MADX & Madrid Stock Index & $02 / 19 / 93-03 / 07 / 08$ \\
(SZ) Switzerland & SMI & Swiss Market Stock Index & $07 / 04 / 88-03 / 07 / 08$ \\
(UK) United Kingdom & ASX & FTSE All-Shares Stock Index & $01 / 03 / 85-03 / 07 / 08$ \\
(US) United States & SPX & S\&P 500 Index & $01 / 05 / 70-03 / 07 / 08$
\end{tabular}

\section{Appendix 1.2 Commodities}

The commodity data are daily closing prices in the spot market. Rubber price data is from Bloomberg, and all other commodities are from the Commodity Research Bureau, Final Markets database.

\begin{tabular}{llll} 
Commodity & Source $^{10}$ & Description & Sample (mm/dd/yy) \\
\hline \hline Energy & & & \\
Crude Oil & NYMEX & West Texas Intermediate crude oil, & 01/02/85 - 03/07/08 \\
& & Cushing OK & \\
Natural Gas & NYMEX & Natural gas, Henry Hub & $10 / 29 / 93-03 / 07 / 08$ \\
Heating Oil & NYMEX & Heating oil \#2, fuel oil & $09 / 02 / 03-03 / 07 / 08$ \\
Gasoline & NYMEX & Gasoline, unleaded, regular & $09 / 02 / 03-03 / 07 / 08$ \\
& & non-oxygenated & \\
Metals & & & \\
Aluminum & LME & Aluminum, high grade & $09 / 01 / 03-03 / 07 / 08$ \\
Copper & NYMEX/COMEX & Copper high grade, scrap \#2 wire & $09 / 02 / 03-03 / 07 / 08$ \\
Gold & NYMEX/COMEX & Gold & $09 / 01 / 03-03 / 07 / 08$ \\
Lead & USGS & Lead pig & $09 / 02 / 03-03 / 07 / 08$ \\
Nickel & LME & Nickel & $09 / 01 / 03-03 / 07 / 08$ \\
Platinum & NYMEX/COMEX & Platinum & $09 / 02 / 03-03 / 07 / 08$ \\
Silver & NYMEX/COMEX & Silver & Tin straights, composite \\
Tin & USGS & Zinc, prime western, domestic & $09 / 02 / 03-03 / 07 / 08$ \\
Zinc & AMM & & $09 / 02 / 03-03 / 07 / 08$ \\
& & & $03 / 07 / 08$
\end{tabular}

${ }^{10}$ NYMEX is the New York Mercantile Exchange, COMEX is the Commodity Exchange, LME is the London Metal Exchange, USGS is the U.S. Geological Survey, AMM is the American Metal Market, USDA is the U.S. Department of Agriculture, MARB is the Malaysian Rubber Board, CBOT is the Chicago Board of Trade, KCBOT is the Kansas City Board of Trade, CME is the Chicago Mercantile Exchange, and NYBOT is the New York Board of Trade. 


\begin{tabular}{|c|c|c|c|}
\hline Commodity & Source & Description & Sample (mm/dd/yy) \\
\hline \multicolumn{4}{|l|}{ Agriculture } \\
\hline Cattle & CME & $\begin{array}{l}\text { Live cattle, choice average, } \\
\text { Texas/Oklahoma }\end{array}$ & 09/02/03 - 03/07/08 \\
\hline Cocoa & NYBOT & Cocoa, Ivory Coast & 09/02/03-03/07/08 \\
\hline Coffee & USDA & Coffee, Brazilian & 09/02/03-03/07/08 \\
\hline Corn & $\mathrm{CBOT}$ & Corn, \#2 yellow & $10 / 25 / 01-03 / 07 / 08$ \\
\hline Cotton & USDA & Cotton, $1-1 / 16$ & 09/02/03-03/07/08 \\
\hline Rubber & MARB & Standard Rubber \#20 & $07 / 20 / 01-03 / 07 / 08$ \\
\hline Soybean & $\mathrm{CBOT}$ & Soybeans, \#1 yellow & 09/02/03 - 03/07/08 \\
\hline Sugar & NYBOT & Sugar \#11, world raw & 09/02/03-03/07/08 \\
\hline Wheat & KCBOT & Wheat, \#2 hard winter & 09/02/03-03/07/08 \\
\hline
\end{tabular}

\section{Appendix 1.3 Foreign Exchange Rates}

Nominal bilateral exchange rates are in units of foreign currency per U.S. dollar. The data for Australia, Brazil, Canada, Denmark, the European Monetary Union, India, Japan, Malaysia, Mexico, New Zealand, Norway, Singapore, South Africa, South Korea, Sweden, Switzerland, Taiwan, Thailand and the United Kingdom are the 12 PM rates from the Federal Reserve Bank of New York. ${ }^{11}$ All other exchange rate data are closing prices from Bloomberg. Countries currently employing a fixed or pegged exchange rate regime are ignored in this study because calculations of temporal dependence are meaningless under fixed prices. Currency classifications are as defined in the 2006 IMF Annual Report on Exchange Arrangements and Exchange Restrictions.

\begin{tabular}{llll} 
Country & Currency & Classification & Sample (mm/dd/yy) \\
\hline \hline Latin America & & & \\
(AR) Argentina & Peso & Managed Float & $02 / 11 / 02-03 / 07 / 08$ \\
(BZ) Brazil & Real & Independent Float & $01 / 15 / 99-03 / 07 / 08$ \\
$(\mathrm{CL})$ Chile & Peso & Independent Float & $09 / 03 / 99-03 / 07 / 08$ \\
$(\mathrm{CO})$ Colombia & Peso & Managed Float & $09 / 26 / 99-03 / 07 / 08$ \\
$(\mathrm{MX})$ Mexico & Peso & Independent Float & $08 / 02 / 96-03 / 07 / 08$ \\
$(\mathrm{PE})$ Peru & Nuevo Sol & Managed Float & $09 / 01 / 97-03 / 07 / 08$
\end{tabular}

\footnotetext{
${ }^{11}$ On the Markets, Foreign Exchange section of the FRBNY website: http://www.ny.frb.org/markets/fxrates/noon.cfm
} 


\begin{tabular}{llll} 
Country & Currency & Classification & Sample $(\mathrm{mm} / \mathrm{dd} / \mathrm{yy})$ \\
\hline \hline Emerging Asia & & & \\
(ID) Indonesia & Rupiah & Managed Float & $08 / 15 / 97-03 / 07 / 08$ \\
(IN) India & Rupee & Managed Float & $01 / 02 / 73-03 / 07 / 08$ \\
(KO) South Korea & Won & Independent Float & $04 / 13 / 81-03 / 07 / 08$ \\
(MA) Malaysia & Ringgit & Managed Float & $01 / 22 / 05-03 / 07 / 08$ \\
(PH) Philippines & Peso & Independent Float & $03 / 16 / 98-03 / 07 / 08$ \\
(RU) Russia & Ruble & Managed Float & $01 / 06 / 99-03 / 07 / 08$ \\
(SI) Singapore & Dollar & Managed Float & $01 / 02 / 81-03 / 07 / 08$ \\
(TH) Thailand & Baht & Managed Float & $07 / 09 / 97-03 / 07 / 08$
\end{tabular}

Middle East and Africa

(IS) Israel

(NG) Nigeria

(SF) South Africa

(TK) Turkey

$\begin{array}{ll}\text { Sheqel } & \text { Independent Float } \\ \text { Naira } & \text { Managed Float } \\ \text { Rand } & \text { Independent Float } \\ \text { New Lira } & \text { Independent Float }\end{array}$

New Lira Independent Float
$12 / 18 / 91-03 / 07 / 08$

01/04/99 - 03/07/08

01/06/71 - 03/07/08

02/28/01 - 03/07/08

\section{Industrialized Economies}
(AL) Australia
Dollar
Independent Float
01/02/75 - 03/07/08
(CA) Canada
Dollar
Independent Float
01/04/71 - 03/07/08
(CZ) Czech Republic
Koruna
Managed Float
01/16/96 - 03/07/08
(EU) European Union ${ }^{12}$
Euro
Independent Float
01/04/99 - 03/07/08
(JA) Japan
Yen
Independent Float
01/04/71 - 03/07/08
(NO) Norway
Krone
Independent Float
01/04/71 - 03/07/08
(NZ) New Zealand
Dollar
Independent Float
01/04/71 - 03/07/08
(PL) Poland
Zloty
Independent Float
04/24/96 - 03/07/08
(SD) Sweden
Krona
Independent Float
01/04/71 - 03/07/08
(SZ) Switzerland
Franc
Independent Float
01/04/71 - 03/07/08
(UK) United Kingdom
Pound
Independent Float
01/04/71 - 03/07/08

\footnotetext{
${ }^{12}$ Austria, Belgium, Finland, France, Germany, Greece, Ireland, Italy, Luxembourg, the Netherlands, Portugal and Spain participate in the European Monetary Union. The European Central Bank may intervene to smooth fluctuations in the euro exchange rate.
} 


\section{Appendix 2 Summary Statistics}

\section{Appendix 2.1 Equity Indices}

\begin{tabular}{|c|c|c|c|c|c|c|}
\hline Country & $\begin{array}{c}\text { Sample } \\
\text { Size }\end{array}$ & Mean & $\begin{array}{l}\text { Standard } \\
\text { Deviation }\end{array}$ & Skewness & $\begin{array}{l}\text { Excess } \\
\text { Kurtosis }\end{array}$ & $\begin{array}{c}\text { Jarque-Bera } \\
\text { Statistic }\end{array}$ \\
\hline Argentina & 1940 & 0.051 & 2.18 & 0.17 & 5.41 & $2377.82 * *$ \\
\hline Brazil & 2879 & 0.120 & 2.01 & 0.61 & 16.31 & $32072.80 * *$ \\
\hline Chile & 4358 & 0.069 & 0.78 & 0.16 & 3.82 & $2666.04 * *$ \\
\hline Colombia & 1528 & 0.167 & 1.51 & -0.06 & 14.38 & $13165.80^{* *}$ \\
\hline Mexico & 4644 & 0.106 & 1.57 & -0.09 & 5.68 & $6253.92 * *$ \\
\hline Peru & 3866 & 0.127 & 1.46 & 0.22 & 6.70 & $7259.93 * *$ \\
\hline Venezuela & 3224 & 0.133 & 1.82 & -0.13 & 13.38 & $24045.15^{* *}$ \\
\hline China & 3121 & 0.060 & 1.84 & 0.55 & 21.33 & $59297.77^{* *}$ \\
\hline Hong Kong & 9042 & 0.057 & 1.85 & -0.37 & 12.39 & $58083.83^{* *}$ \\
\hline Indonesia & 5795 & 0.059 & 1.57 & 4.00 & 97.61 & $2316205.03 * *$ \\
\hline India & 5639 & 0.051 & 1.59 & -0.06 & 4.61 & $5005.44 * *$ \\
\hline Korea & 6620 & 0.043 & 1.62 & -0.16 & 4.59 & $5847.42 * *$ \\
\hline Malaysia & 7316 & 0.036 & 1.40 & -0.61 & 32.44 & $321301.57^{* *}$ \\
\hline Philippines & 5079 & 0.027 & 1.67 & 0.10 & 9.49 & $19048.88^{* *}$ \\
\hline Russia & 2995 & 0.078 & 2.70 & -0.42 & 6.50 & $5357.90 * *$ \\
\hline Singapore & 7951 & 0.036 & 1.21 & -1.32 & 34.04 & $386172.07^{* *}$ \\
\hline Taiwan & 8165 & 0.046 & 1.76 & -0.23 & 3.77 & $4903.65^{* *}$ \\
\hline Thailand & 4803 & 0.029 & 1.70 & 0.02 & 6.23 & $7773.66^{* *}$ \\
\hline Israel & 2301 & 0.063 & 1.74 & -0.17 & 3.70 & $1325.61 * *$ \\
\hline Kuwait & 736 & 0.228 & 1.27 & -0.50 & 5.97 & $1122.54 * *$ \\
\hline Nigeria & 2186 & 0.081 & 0.86 & -0.98 & 15.52 & $22303.69 * *$ \\
\hline Saudi Arabia & 2025 & 0.063 & 1.62 & -0.94 & 15.32 & $20113.67^{* *}$ \\
\hline South Africa & 3054 & 0.050 & 1.20 & -0.74 & 7.86 & $8144.32 * *$ \\
\hline Turkey & 4403 & 0.163 & 2.93 & 0.02 & 3.48 & $2220.95^{* *}$ \\
\hline UAE & 627 & 0.252 & 2.31 & 0.14 & 3.94 & $408.59 * *$ \\
\hline Australia & 6978 & 0.036 & 0.95 & -4.53 & 127.01 & $4714368.66^{* *}$ \\
\hline Belgium & 4679 & 0.030 & 0.89 & 0.05 & 7.11 & $9847.77^{* *}$ \\
\hline Canada & 7602 & 0.035 & 0.85 & -0.99 & 13.53 & $59242.83^{* *}$ \\
\hline Czech Republic & 3218 & 0.014 & 1.21 & -0.22 & 3.09 & $1307.13 * *$ \\
\hline Denmark & 2975 & 0.043 & 0.94 & -0.51 & 2.55 & $933.22 * *$ \\
\hline France & 4234 & 0.030 & 1.14 & -0.21 & 3.45 & $2130.20 * *$ \\
\hline Germany & 4965 & 0.038 & 1.30 & -0.56 & 6.98 & $10339.31^{* *}$ \\
\hline Hungary & 4163 & 0.074 & 1.60 & -0.79 & 13.69 & $32927.86 * *$ \\
\hline Italy & 8545 & 0.027 & 1.26 & -0.46 & 5.22 & $10001.44^{* *}$ \\
\hline Japan & 9027 & 0.017 & 1.04 & -0.52 & 11.62 & $51222.52^{* *}$ \\
\hline Netherlands & 6275 & 0.035 & 1.28 & -0.32 & 8.22 & $17771.00 * *$ \\
\hline Norway & 2981 & 0.037 & 1.19 & -0.53 & 3.38 & $1560.75^{* *}$ \\
\hline New Zealand & 3902 & 0.041 & 0.80 & 0.00 & 8.70 & $12299.44 * *$ \\
\hline Poland & 3348 & 0.053 & 1.90 & -0.17 & 7.36 & $7572.63 * *$ \\
\hline Sweden & 1995 & -0.004 & 1.41 & -0.11 & 2.42 & $490.24^{* *}$ \\
\hline Spain & 3641 & 0.045 & 1.17 & -0.36 & 3.22 & $1649.38^{* *}$ \\
\hline Switzerland & 4824 & 0.029 & 1.13 & -0.52 & 7.03 & $10142.03 * *$ \\
\hline UK & 5864 & 0.033 & 0.96 & -0.81 & 11.71 & $34140.18^{* *}$ \\
\hline US & 9317 & 0.040 & 0.99 & -1.43 & 34.83 & $474220.14^{* *}$ \\
\hline
\end{tabular}

* and ${ }^{* *}$ represent significance at the 95 and 99 percent confidence levels, respectively 
Appendix 2.2 Commodities

\begin{tabular}{|c|c|c|c|c|c|c|}
\hline Commodity & $\begin{array}{l}\text { Sample } \\
\text { Size }\end{array}$ & Mean & $\begin{array}{l}\text { Standard } \\
\text { Deviation }\end{array}$ & Skewness & $\begin{array}{l}\text { Excess } \\
\text { Kurtosis }\end{array}$ & $\begin{array}{c}\text { Jarque-Bera } \\
\text { Statistic }\end{array}$ \\
\hline Crude Oil & 5630 & 0.016 & 2.45 & -1.22 & 18.93 & $85435.26^{* *}$ \\
\hline Gasoline & 1086 & 0.090 & 2.96 & -0.15 & 7.08 & $2271.70 * *$ \\
\hline Natural Gas & 3405 & 0.080 & 4.89 & 0.70 & 24.74 & $87144.91^{* *}$ \\
\hline Heating Oil & 1086 & 0.114 & 2.33 & 0.26 & 1.06 & $63.64 * *$ \\
\hline Copper & 1086 & 0.109 & 1.99 & -0.50 & 3.10 & $480.71 * *$ \\
\hline Aluminum & 1114 & 0.074 & 1.45 & -0.25 & 2.11 & $219.03^{* *}$ \\
\hline Lead & 1087 & 0.109 & 2.03 & -0.37 & 5.89 & $1597.30^{* *}$ \\
\hline Nickel & 1114 & 0.117 & 2.65 & -0.35 & 3.32 & $535.69 * *$ \\
\hline Tin & 1097 & 0.111 & 1.69 & -0.40 & 3.79 & $685.51^{* *}$ \\
\hline Zinc & 1097 & 0.079 & 2.00 & -0.50 & 2.60 & $356.57^{* *}$ \\
\hline Gold & 1166 & 0.078 & 1.11 & -0.57 & 2.58 & $385.74 * *$ \\
\hline Platinum & 1097 & 0.086 & 1.25 & -0.02 & 5.48 & $1372.32 * *$ \\
\hline Silver & 1164 & 0.104 & 2.04 & -1.41 & 9.79 & $5032.06 * *$ \\
\hline Cotton & 1087 & 0.017 & 1.73 & 0.29 & 11.91 & $6433.98 * *$ \\
\hline Rubber & 1548 & 0.088 & 0.87 & -0.28 & 2.48 & $416.12^{* *}$ \\
\hline Corn & 1537 & 0.059 & 1.76 & 0.15 & 1.23 & $103.49 * *$ \\
\hline Wheat & 1092 & 0.088 & 2.28 & -0.49 & 64.15 & $187269.43^{* *}$ \\
\hline Soybeans & 1090 & 0.057 & 1.75 & -0.82 & 4.35 & $983.71^{* *}$ \\
\hline Cattle & 1108 & 0.022 & 1.43 & 0.24 & 3.64 & $622.91^{* *}$ \\
\hline Cocoa & 1086 & 0.044 & 1.73 & -0.24 & 3.39 & $530.14^{* *}$ \\
\hline Coffee & 1085 & 0.084 & 1.98 & 0.30 & 4.31 & $857.82^{* *}$ \\
\hline Sugar & 1086 & 0.071 & 1.91 & -0.13 & 2.27 & $236.46 * *$ \\
\hline
\end{tabular}

* and ${ }^{* *}$ represent significance at the 95 and 99 percent confidence levels, respectively 
Appendix 2.3 Foreign Exchange Rates

\begin{tabular}{|c|c|c|c|c|c|c|}
\hline Country & $\begin{array}{l}\text { Sample } \\
\text { Size }\end{array}$ & Mean & $\begin{array}{l}\text { Standard } \\
\text { Deviation }\end{array}$ & Skewness & $\begin{array}{c}\text { Excess } \\
\text { Kurtosis }\end{array}$ & $\begin{array}{c}\text { Jarque-Bera } \\
\text { Statistic }\end{array}$ \\
\hline Argentina & 1544 & 0.030 & $\bar{~} 1.15$ & 3.18 & 102.82 & "682741.37** \\
\hline Brazil & 2218 & -0.004 & 1.07 & 0.54 & 13.98 & $18173.92 * *$ \\
\hline Chile & 2175 & -0.007 & 0.54 & 0.07 & 2.14 & $414.97 * *$ \\
\hline Colombia & 2163 & -0.003 & 0.53 & 0.06 & 6.49 & $3803.08 * *$ \\
\hline Mexico & 2808 & 0.010 & 0.51 & 0.87 & 8.19 & $8195.30 * *$ \\
\hline Peru & 543 & 0.049 & 0.30 & -0.01 & 8.73 & $1726.16^{* *}$ \\
\hline Indonesia & 2695 & 0.036 & 1.85 & 1.71 & 36.17 & $148223.94^{* *}$ \\
\hline India & 8477 & 0.017 & 0.47 & 4.71 & 129.04 & $5912848.31 * *$ \\
\hline Korea & 6427 & 0.003 & 0.58 & 3.45 & 158.07 & $6704119.60 * *$ \\
\hline Malaysia & 638 & -0.027 & 0.25 & -0.05 & 3.24 & $279.5911^{* *}$ \\
\hline Philippines & 2561 & 0.001 & 0.56 & -7.75 & 218.71 & $5130106.64 * *$ \\
\hline Russia & 2355 & 0.002 & 0.37 & 1.98 & 75.65 & $563129.97^{* *}$ \\
\hline Singapore & 6571 & -0.008 & 0.33 & -0.80 & 15.94 & $70261.65^{* *}$ \\
\hline Thailand & 2587 & -0.002 & 0.73 & -0.51 & 15.62 & $26420.83 * *$ \\
\hline Israel & 3819 & 0.010 & 0.43 & 1.47 & 25.24 & $102758.53 * *$ \\
\hline Nigeria & 2263 & 0.011 & 1.47 & 0.27 & 16.27 & $24986.60 * *$ \\
\hline South Africa & 8933 & 0.028 & 0.83 & 1.93 & 53.89 & $1086480.52 * *$ \\
\hline Turkey & 1832 & 0.018 & 1.24 & 1.43 & 23.55 & $42949.21 * *$ \\
\hline Australia & 8015 & 0.002 & 0.62 & 4.62 & 128.27 & $5523084.78 * *$ \\
\hline Canada & 8977 & -0.001 & 0.32 & -0.01 & 3.82 & $5445.18 * *$ \\
\hline Czech Republic & 3122 & -0.016 & 0.69 & 0.53 & 8.09 & $8663.15^{* *}$ \\
\hline European Union & 2226 & -0.013 & 0.58 & -0.02 & 0.85 & $67.46 * *$ \\
\hline Japan & 8963 & -0.013 & 0.62 & -0.41 & 5.94 & $13425.10 * *$ \\
\hline Norway & 8967 & -0.004 & 0.59 & 0.36 & 7.98 & $24018.13 * *$ \\
\hline New Zealand & 8949 & 0.002 & 0.67 & 2.72 & 66.20 & $1644907.54 * *$ \\
\hline Poland & 3049 & -0.006 & 0.64 & 0.28 & 2.82 & $1049.42 * *$ \\
\hline Sweden & 8967 & -0.002 & 0.59 & 1.02 & 19.68 & $146297.76^{* *}$ \\
\hline Switzerland & 8969 & -0.016 & 0.71 & 0.01 & 3.77 & $5317.29 * *$ \\
\hline UK & 8969 & 0.001 & 0.57 & 0.14 & 4.20 & $6608.25^{* *}$ \\
\hline
\end{tabular}

${ }^{*}$ and ${ }^{* *}$ represent significance at the 95 and 99 percent confidence levels, respectively 


\section{Appendix 3 Random Walk Hypothesis Tests}
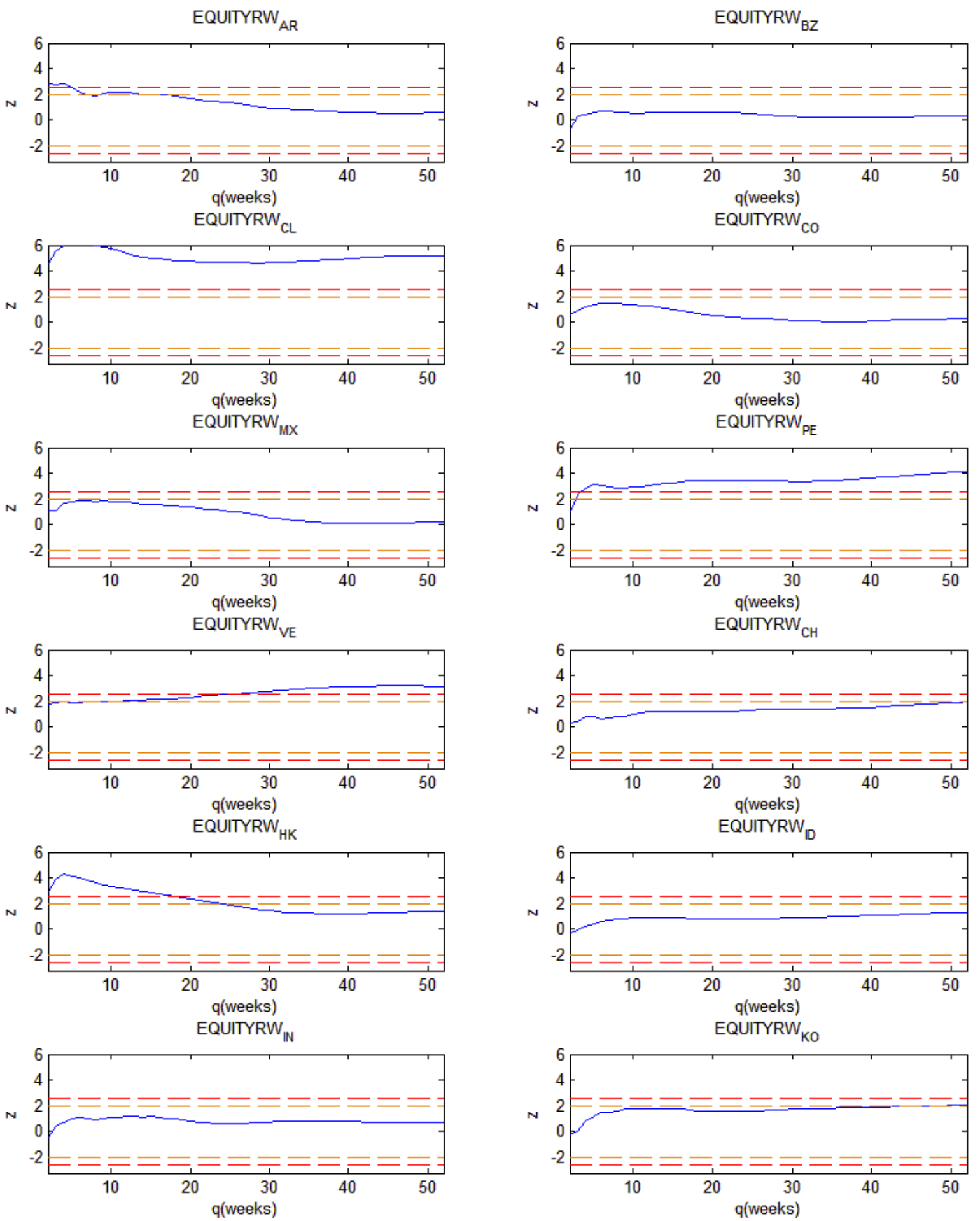
EQUITYRW

N

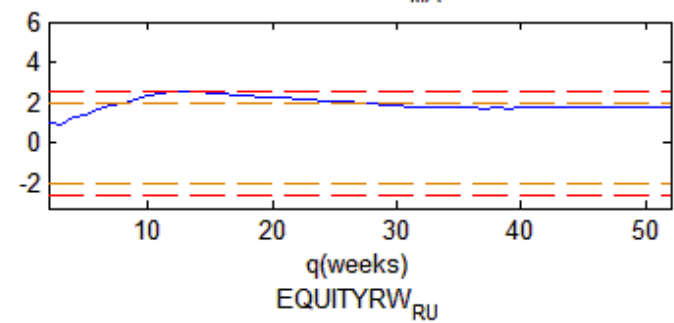

N
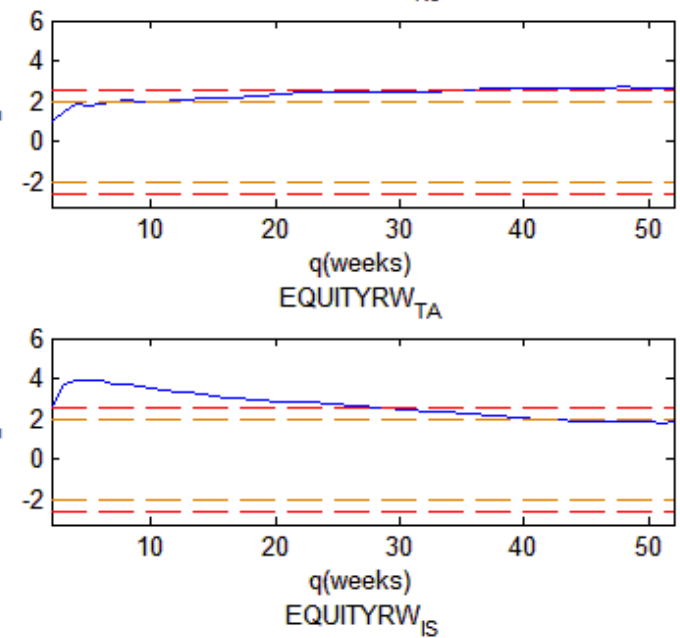

N

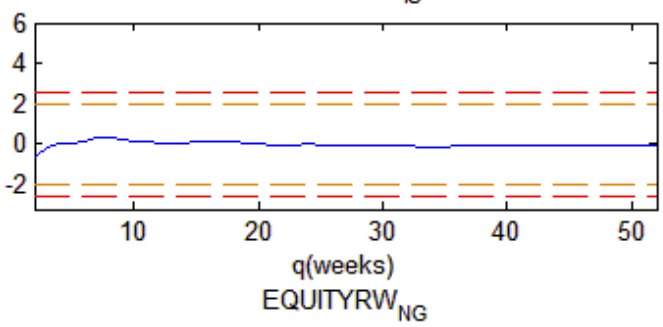

N

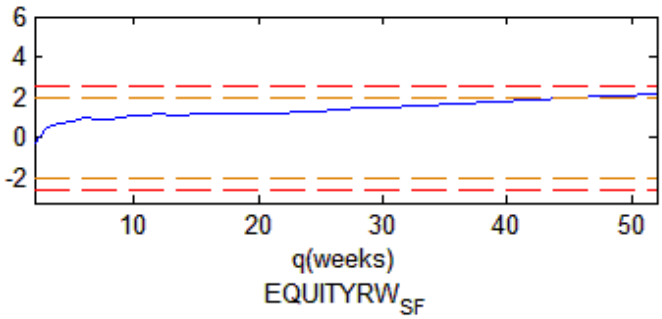

N

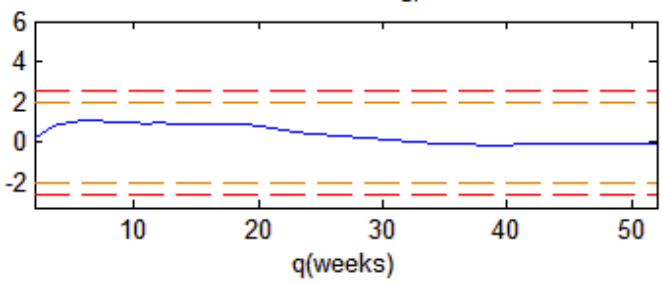

EQUITYRW

N

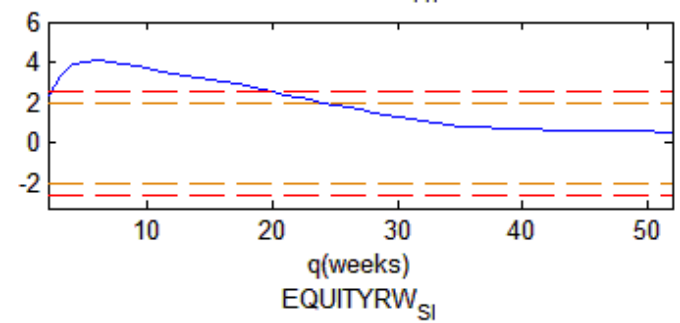

N

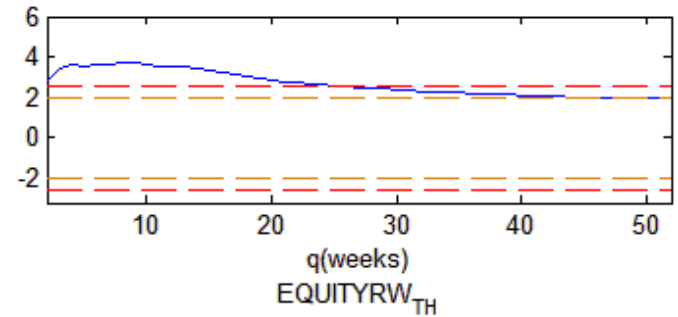

N

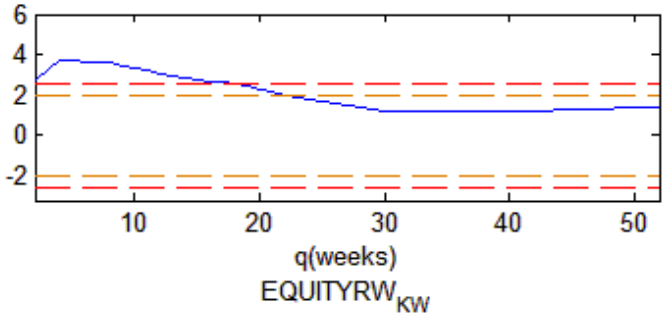

$N$
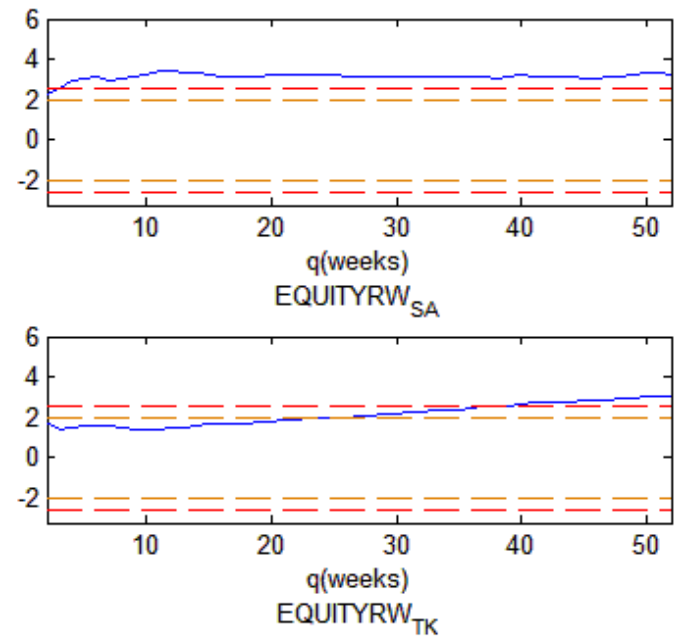

N

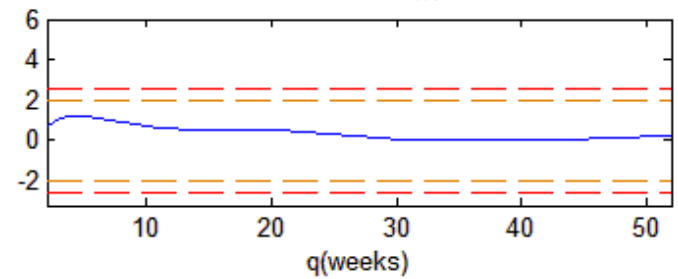



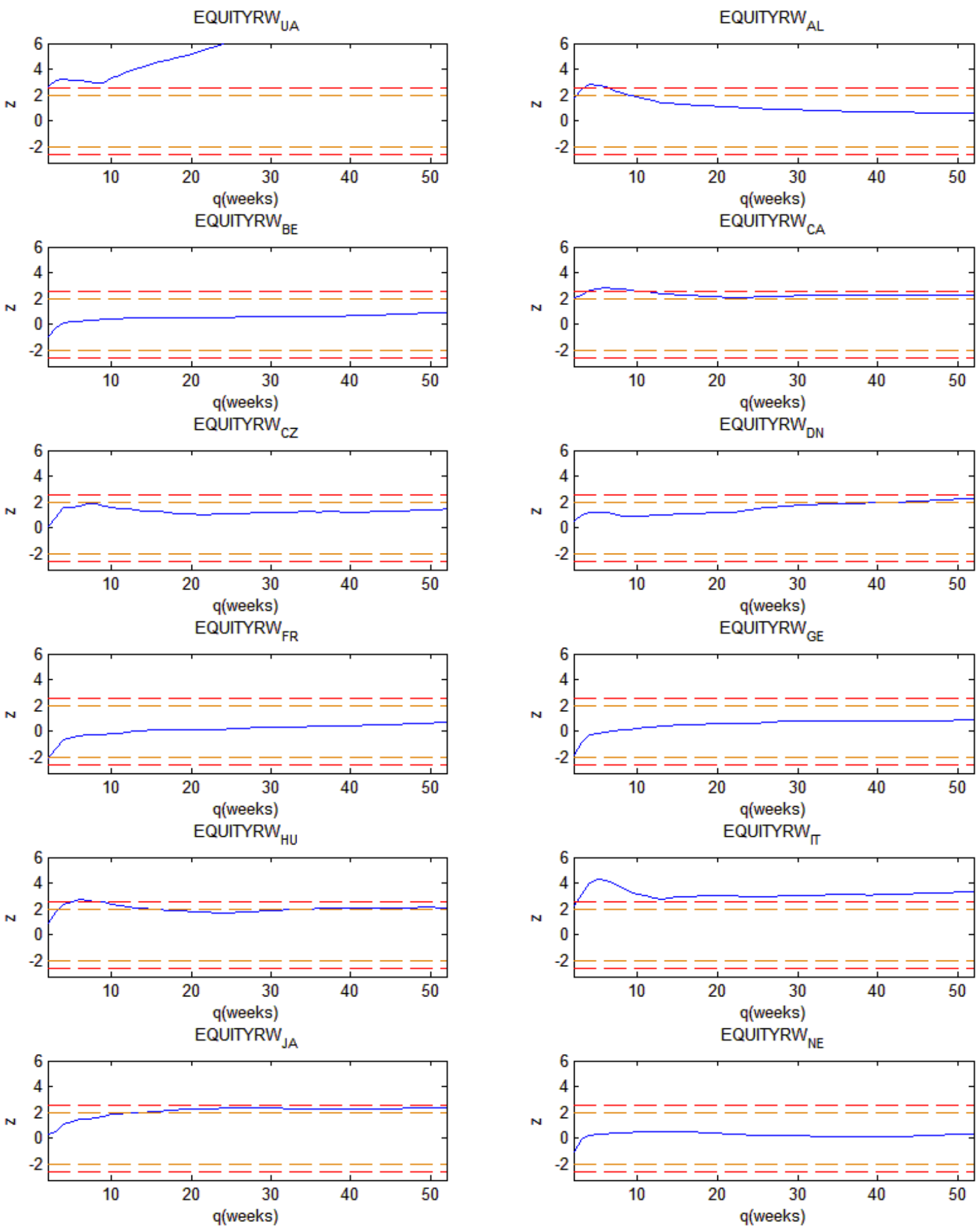
EQUITYRW $_{\text {NO }}$

N

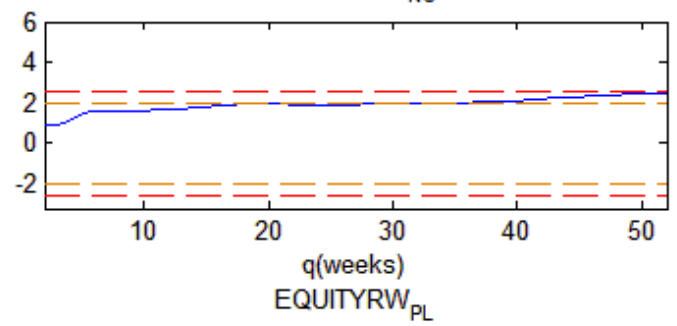

N

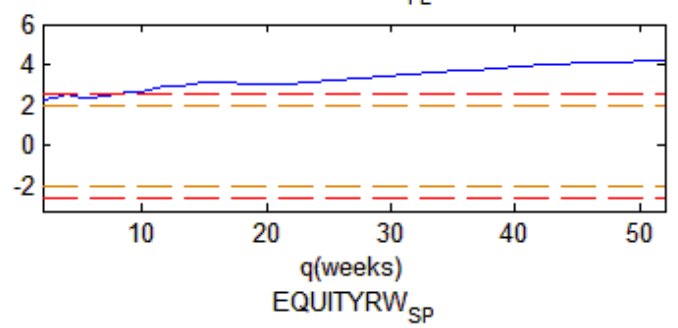

$\sqrt[6]{2}$ EQUITYRW $_{U K}$

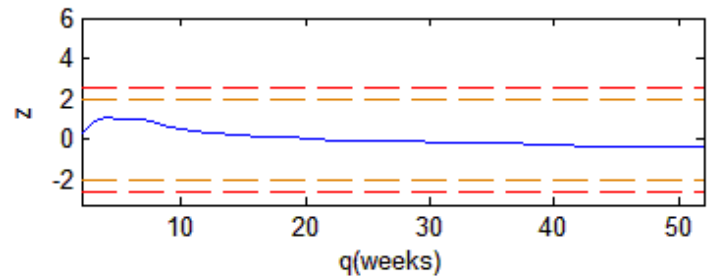

EQUITYRW $_{\mathrm{NZ}}$

N

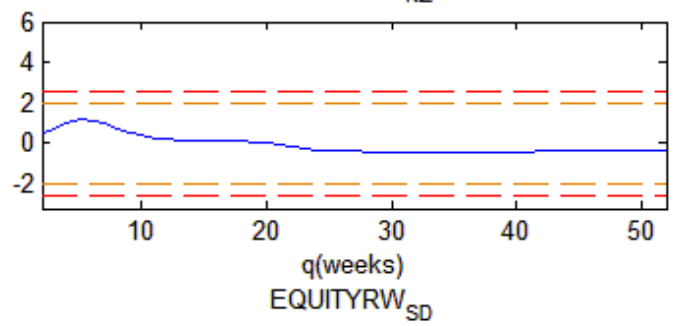

N

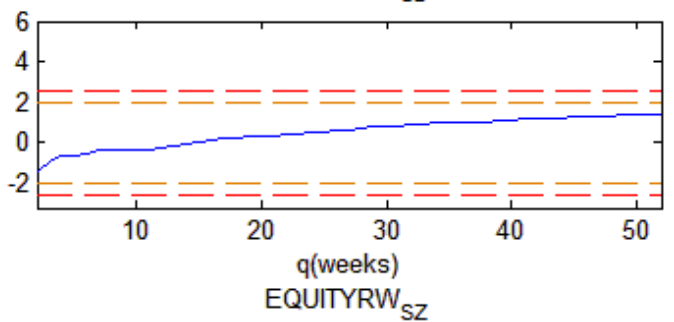

N

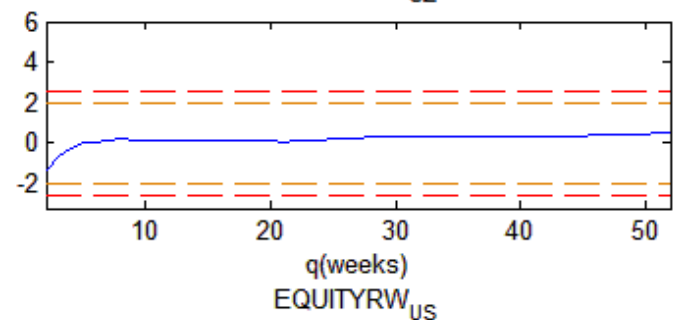

N

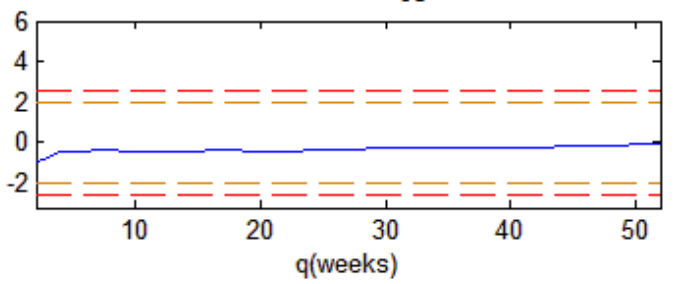


COMMODITYRW CRUDEOIL $_{\text {L }}$

N

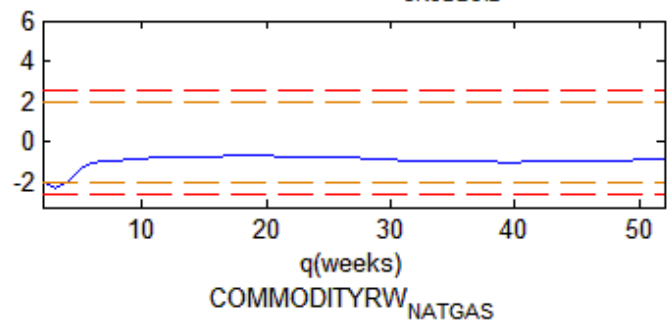

N
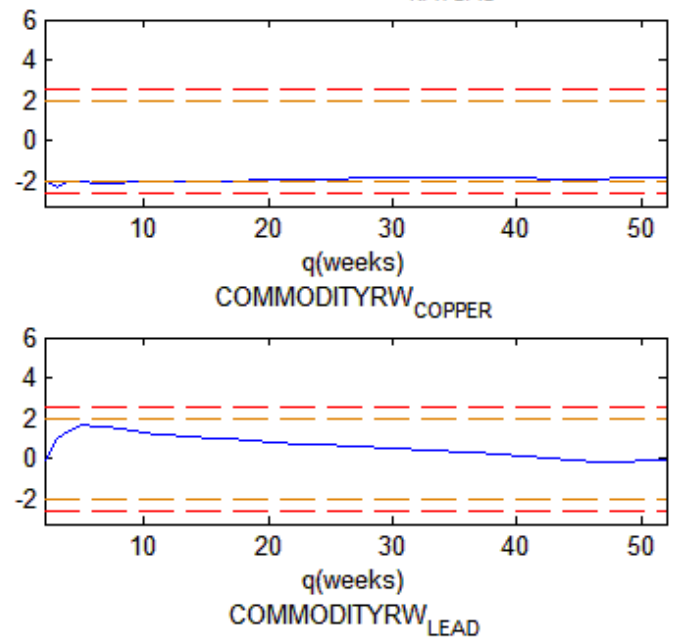

N

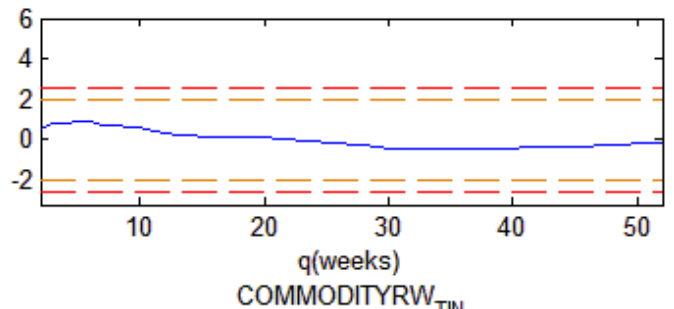

N

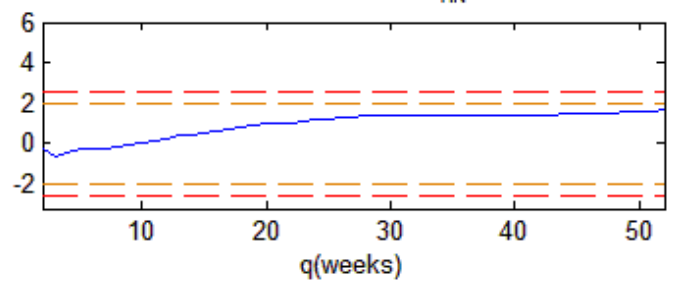

COMMODITYRW $_{\text {GOLD }}$

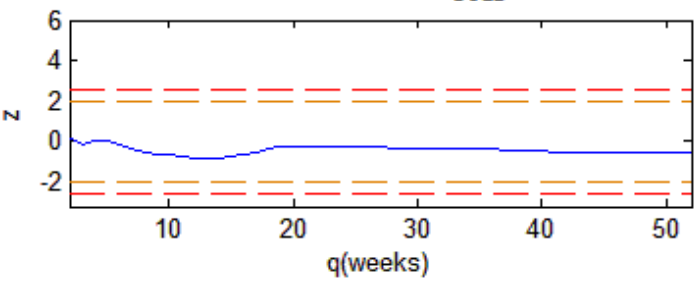

COMMODITYRW GASOLINE

$N$

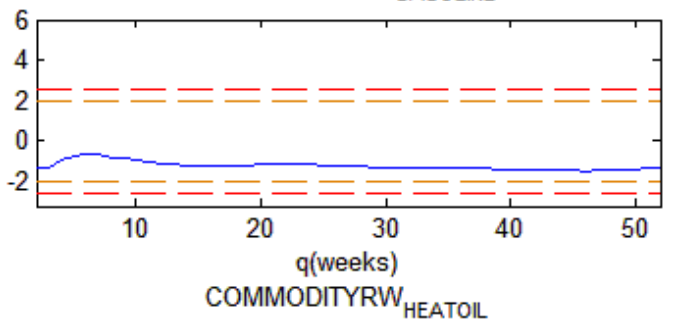

N

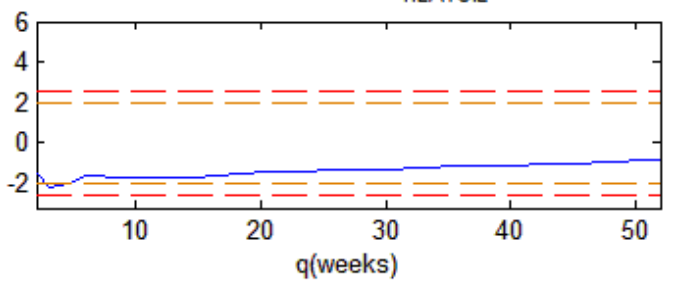

COMMODITYRW ALUMINUM $_{\text {ALU }}$

N
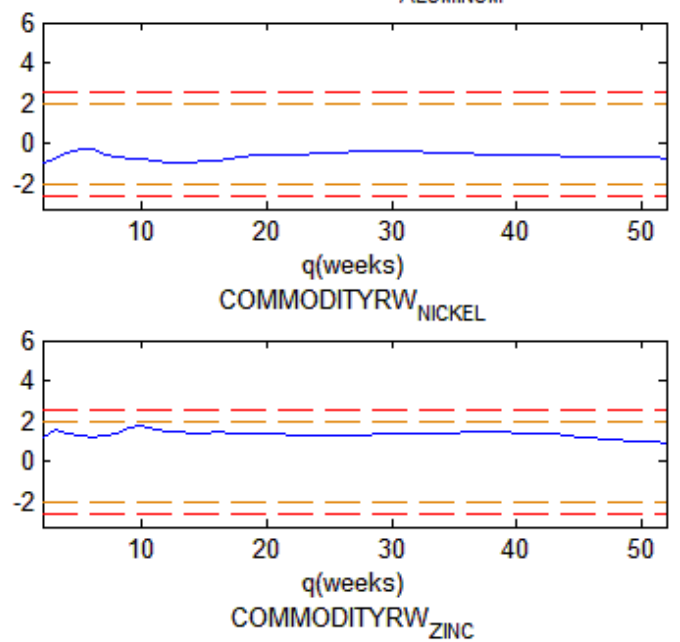

N

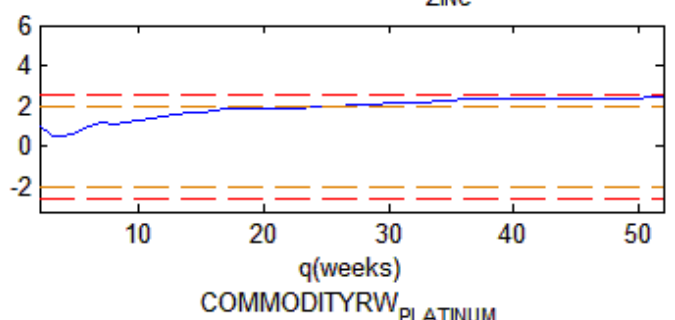

N

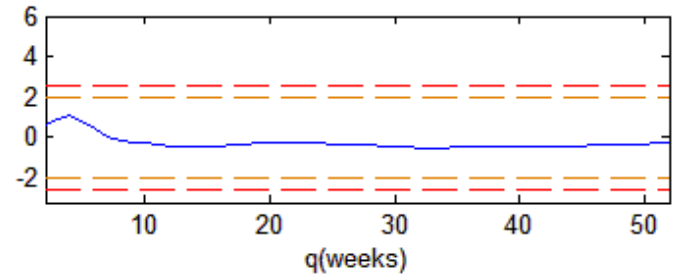



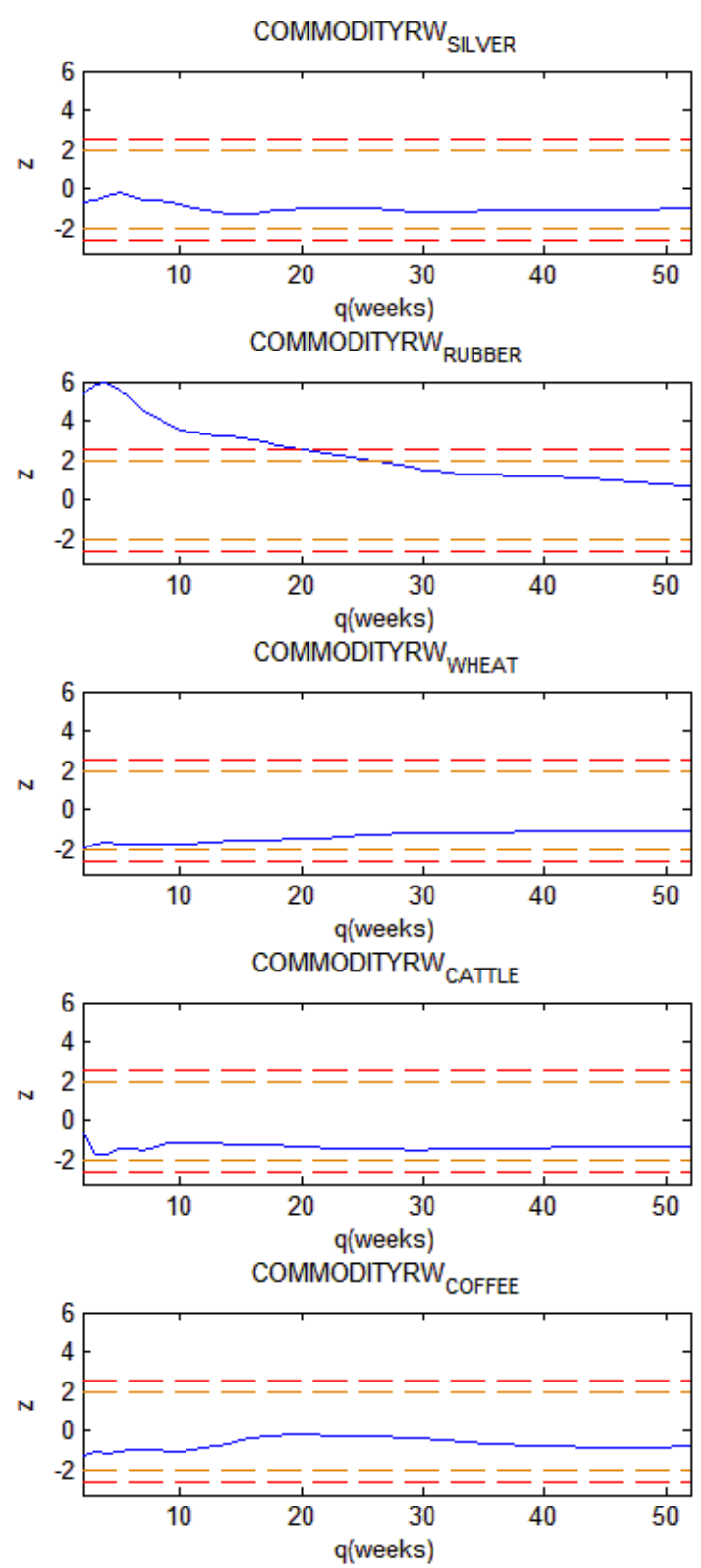
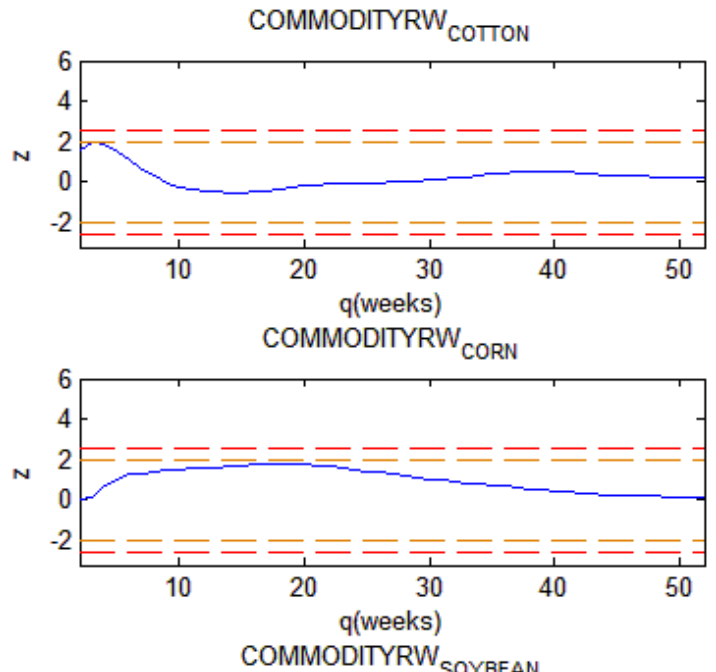

N
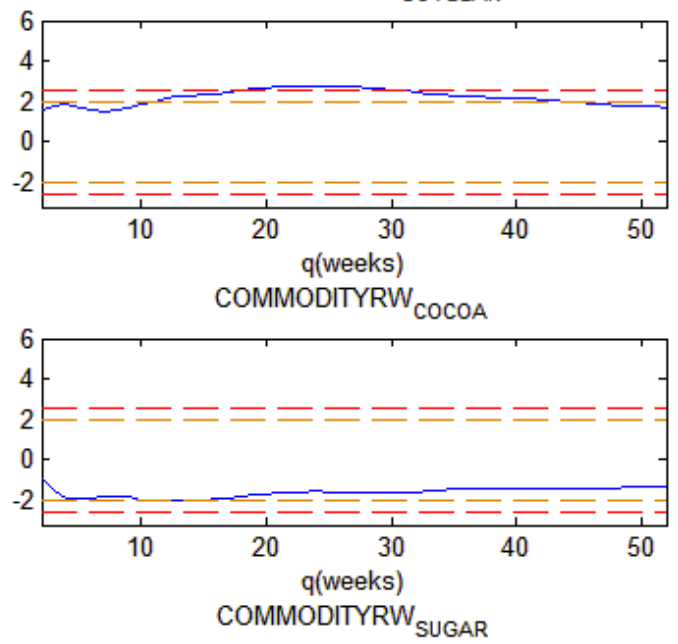

N

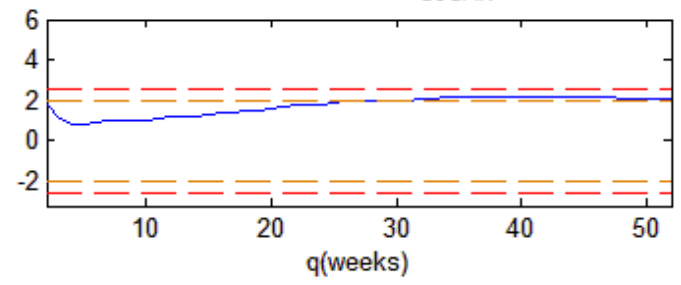


FOREXRW $_{\text {AR }}$

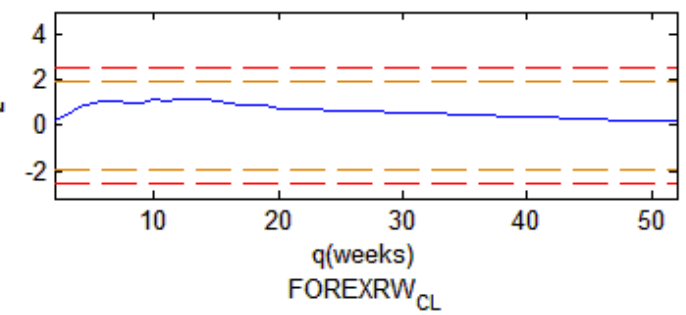

N
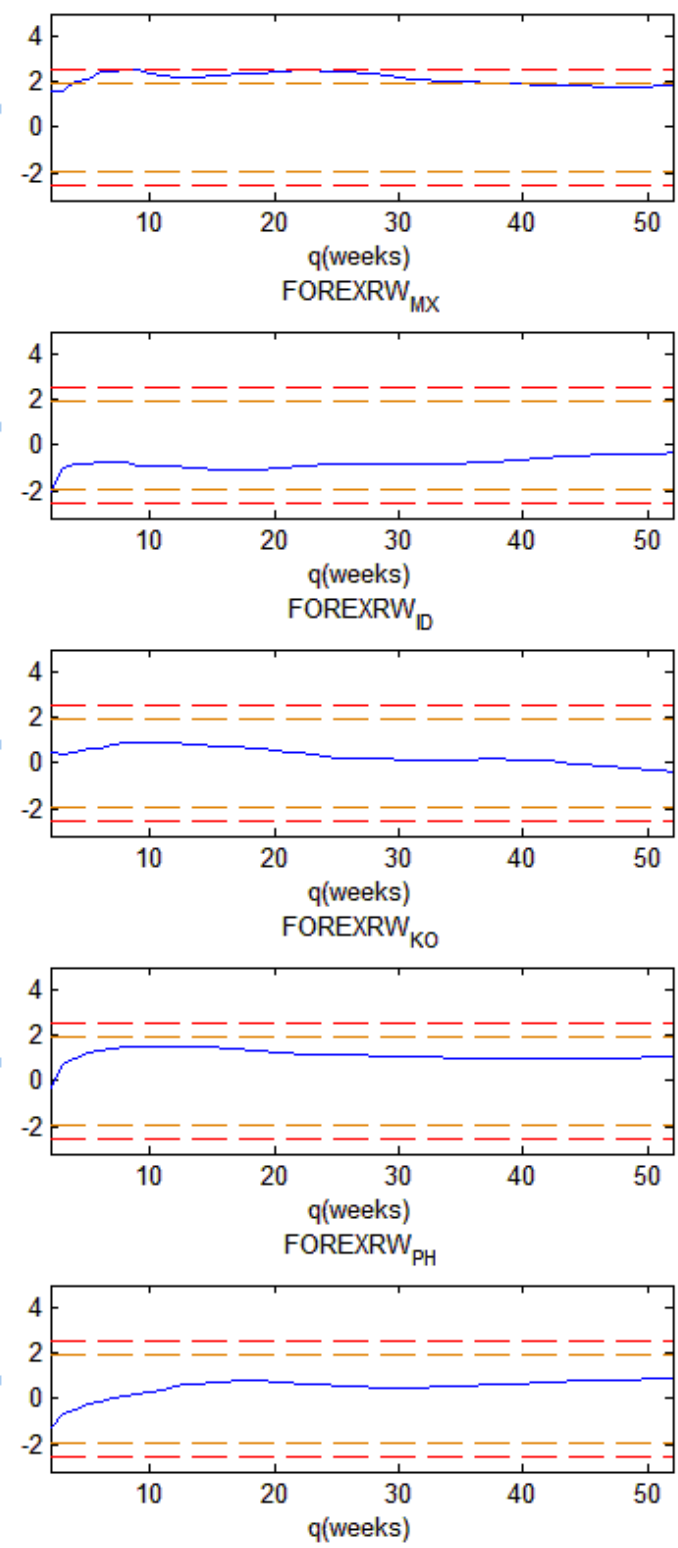

FOREXRW $_{B Z}$
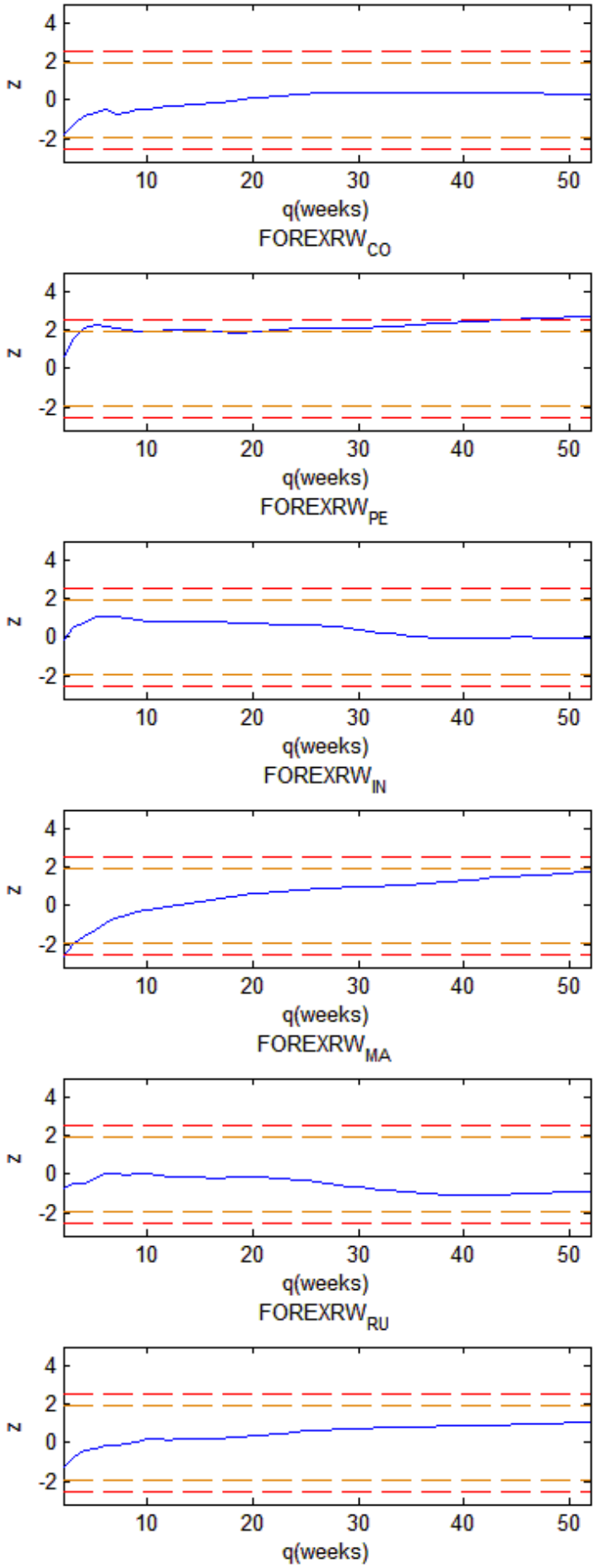

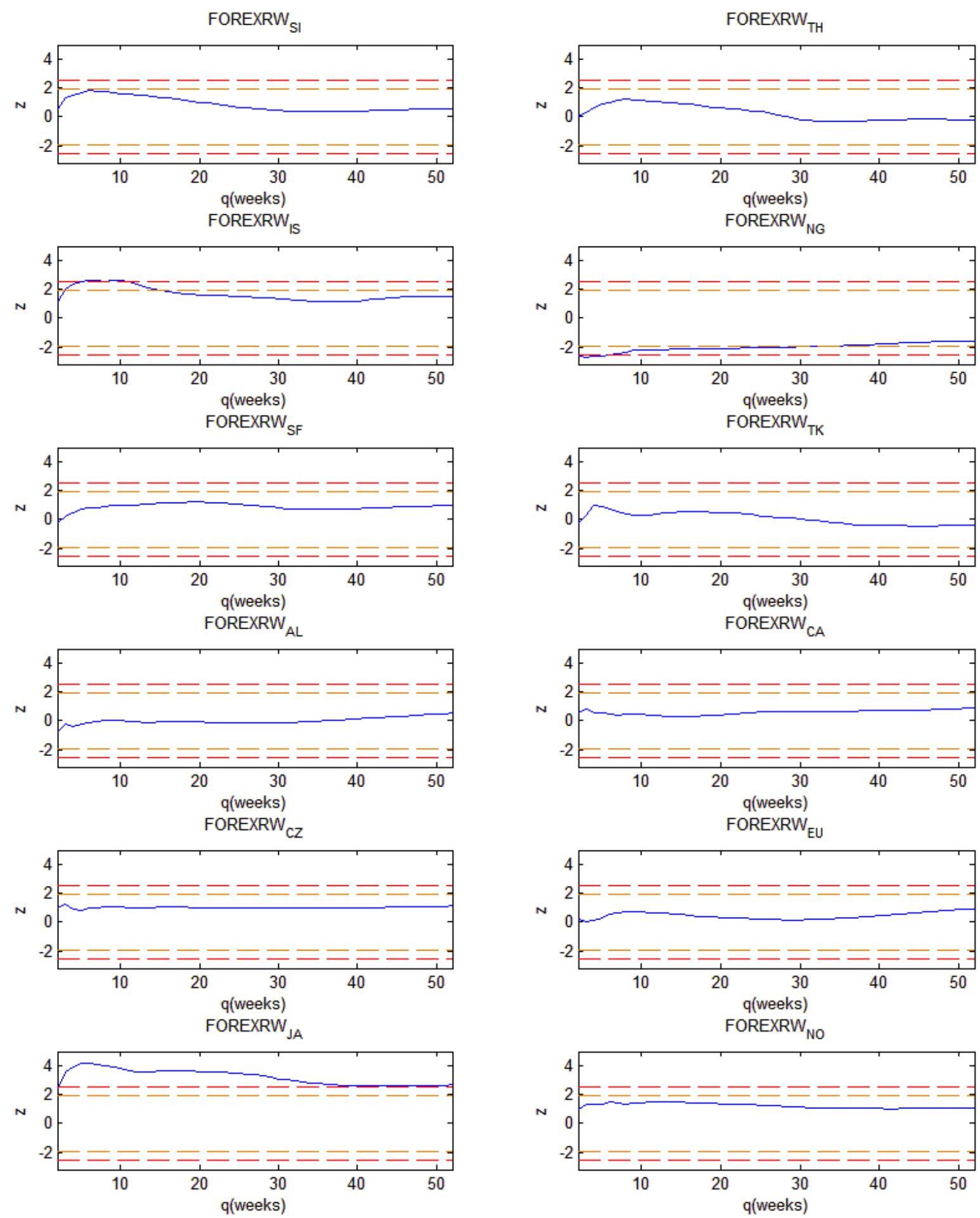
N

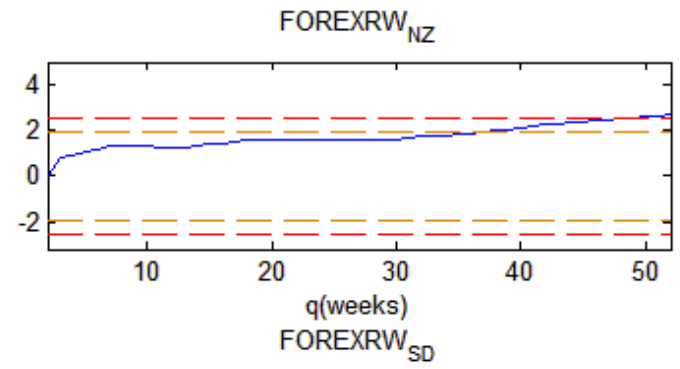

$N$

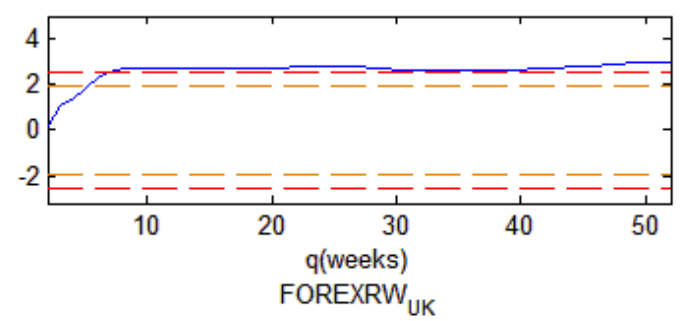

$N$

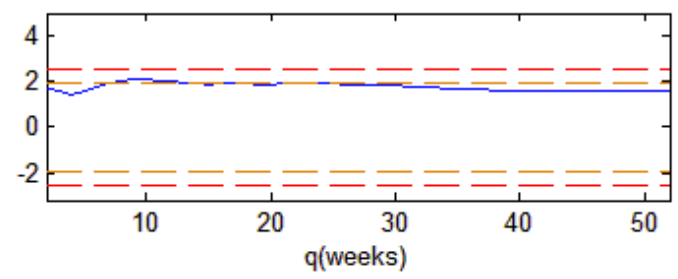

FOREXRW
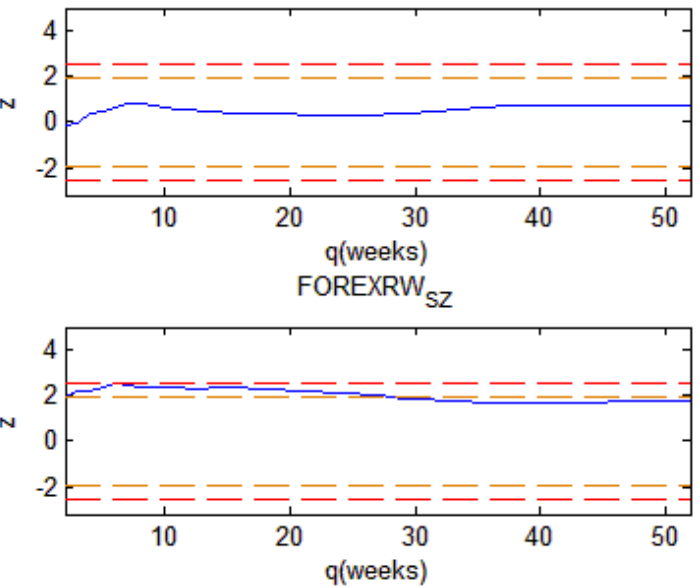


\section{Appendix 4 Long Memory Hypothesis Tests}
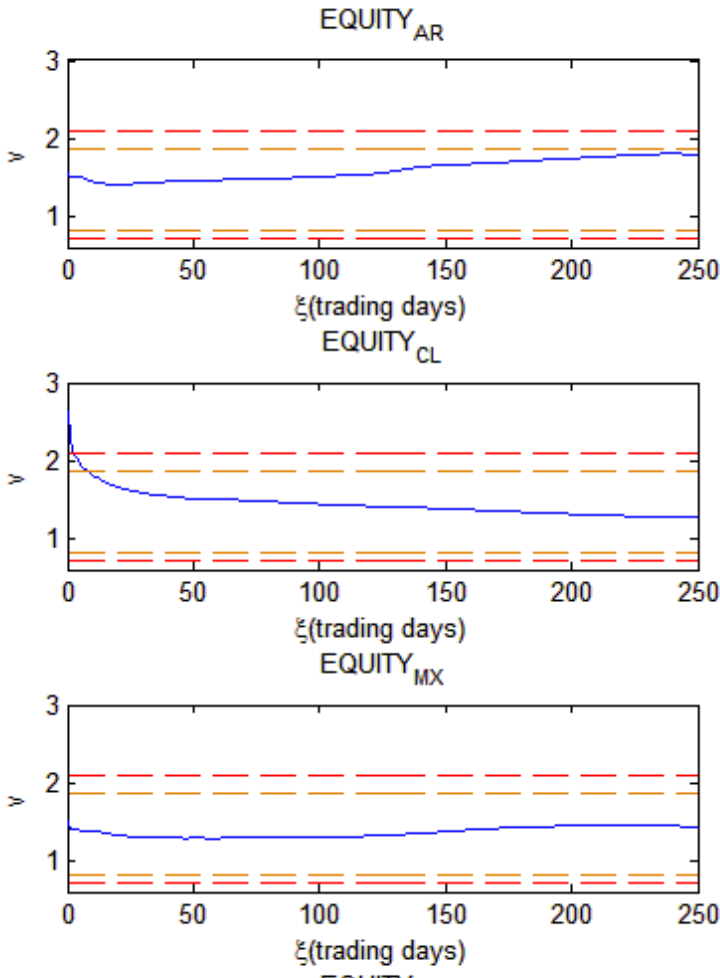

EQUITY VE

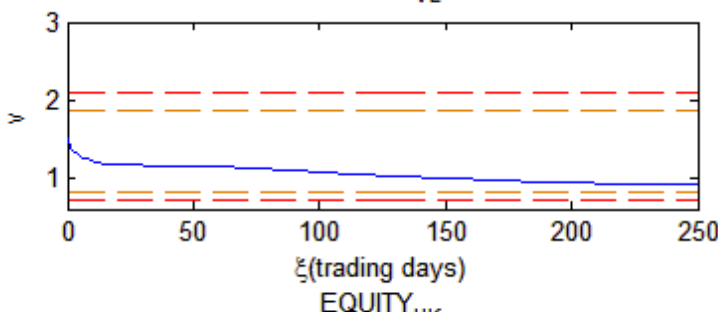

EQUITY $_{\mathrm{HK}}$
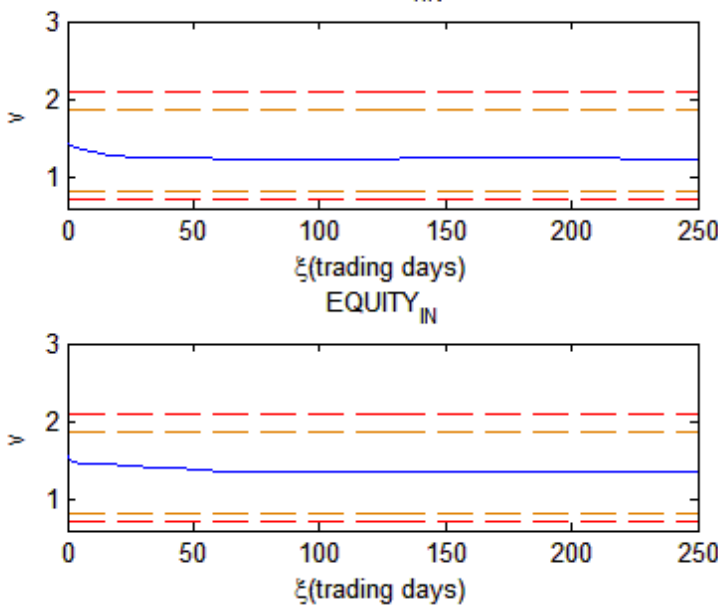
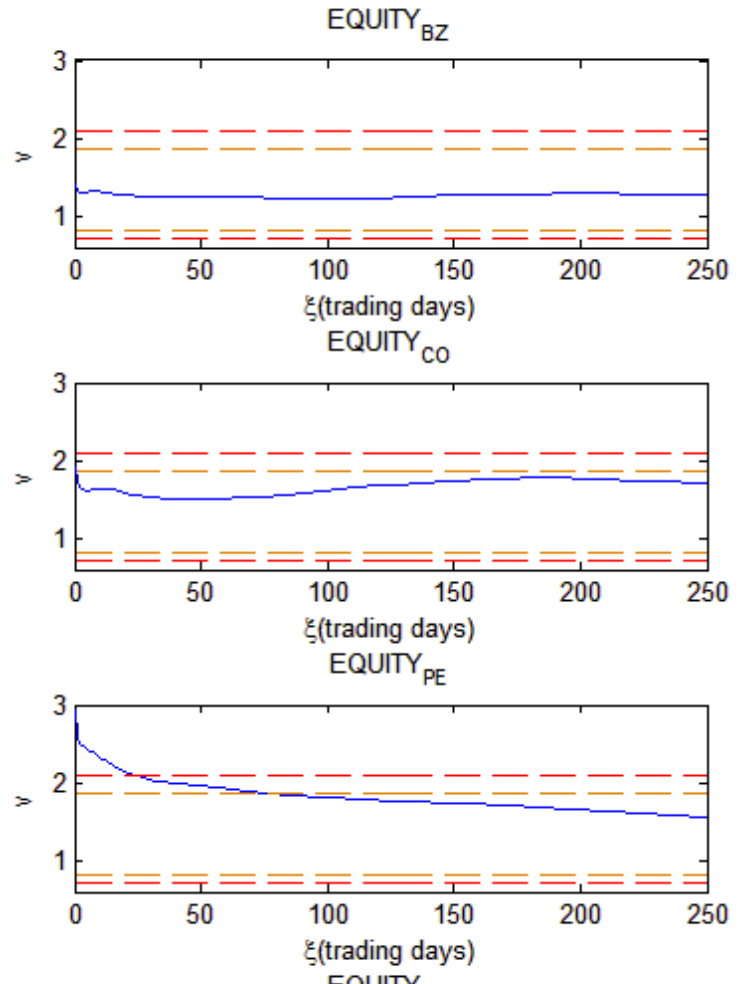

EQUITY

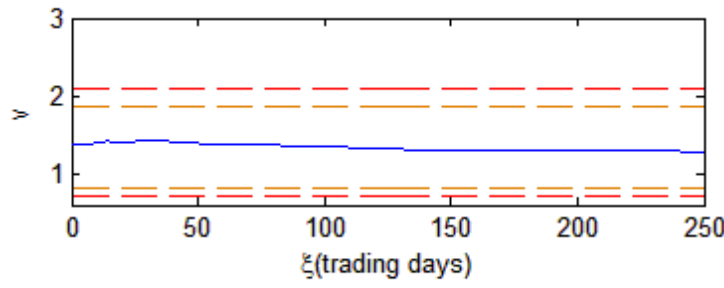

EQUITY
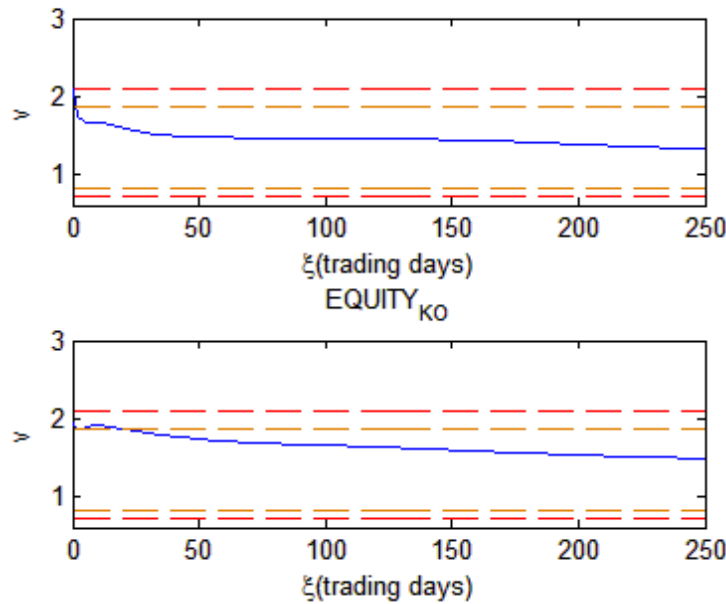

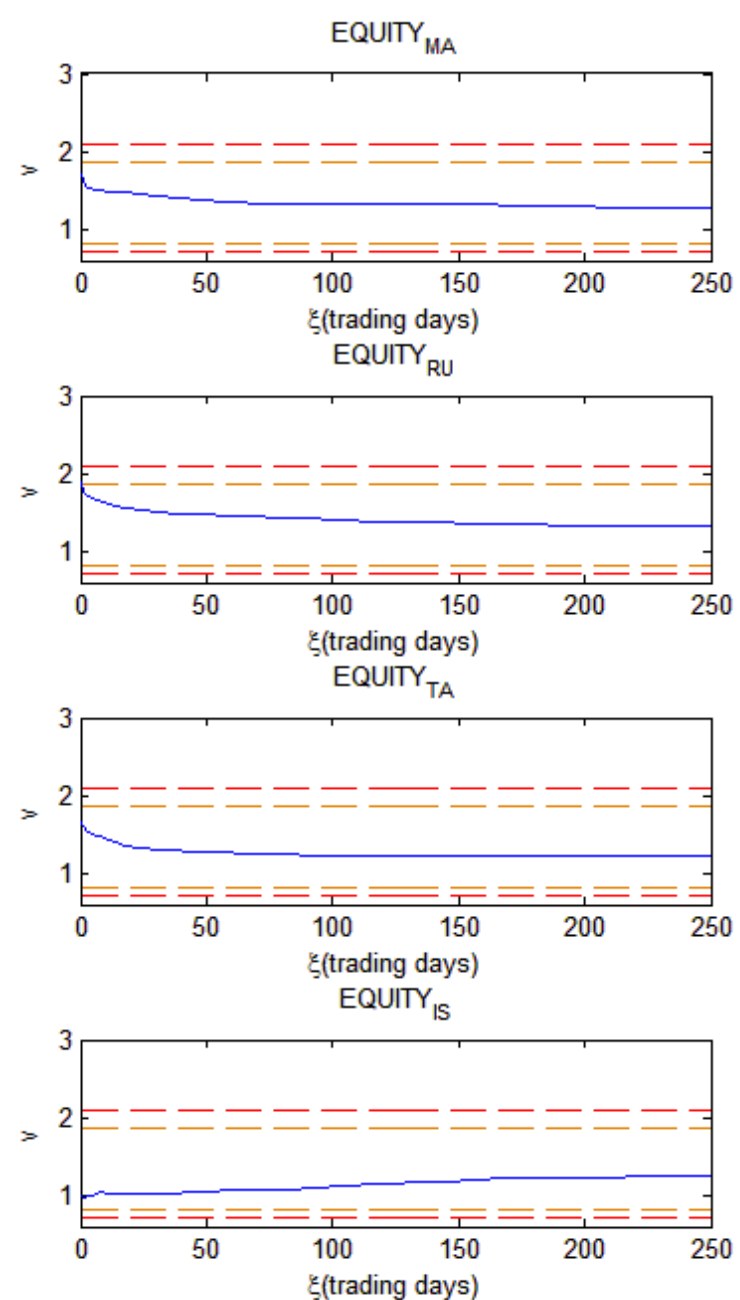
EQUITY $_{N G}$

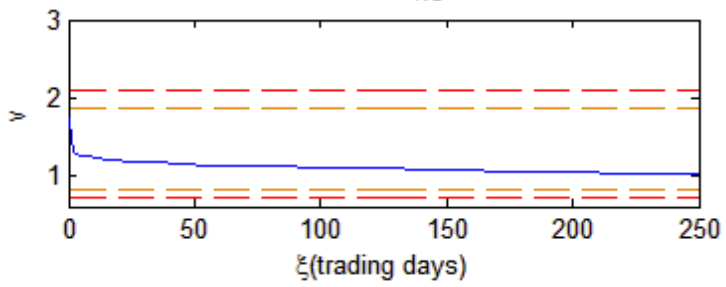

EQUITY $_{\text {SF }}$

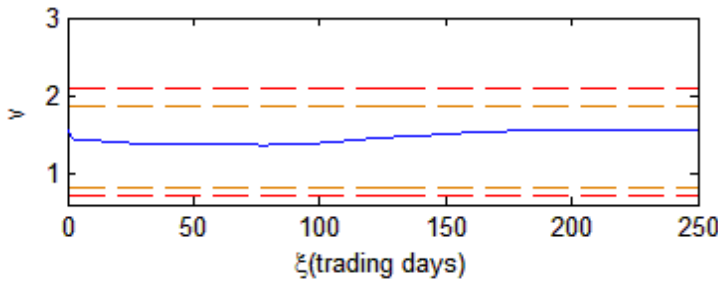

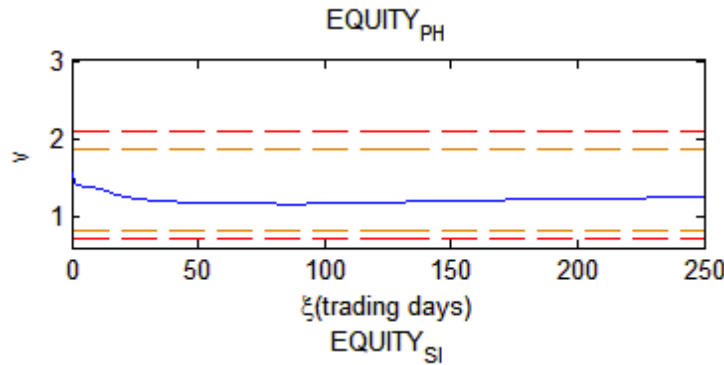
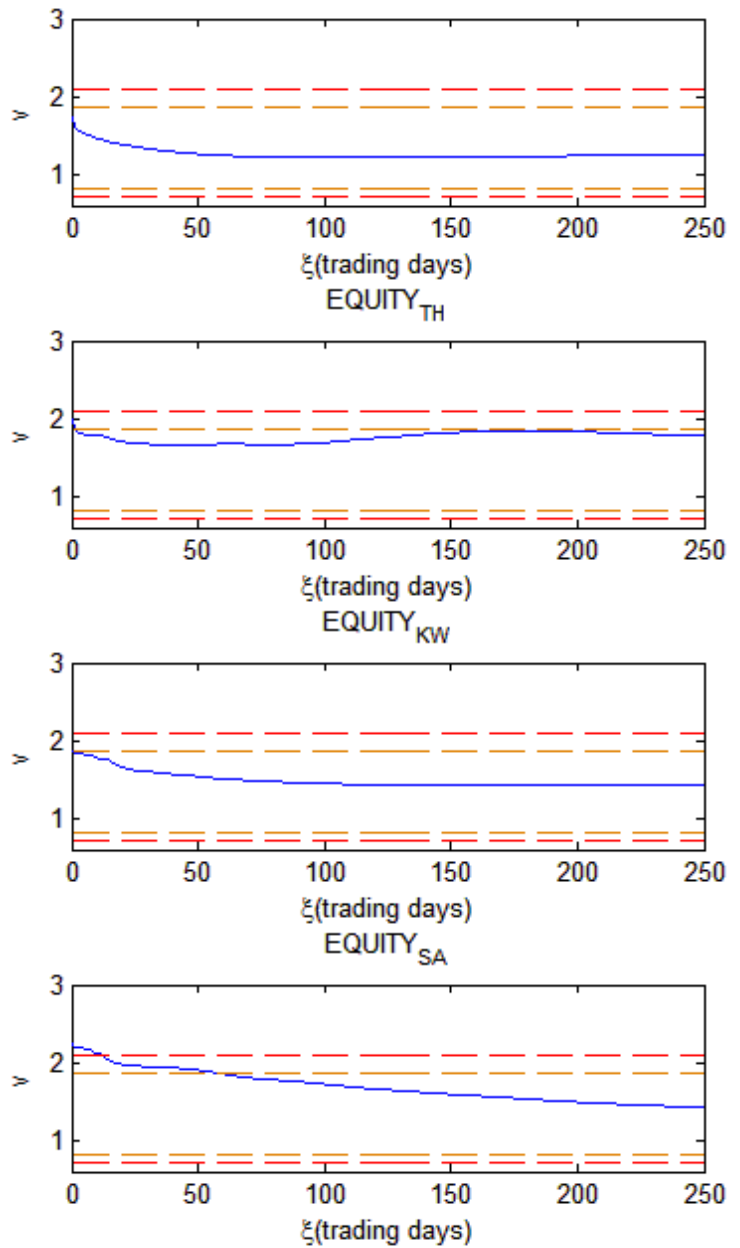
EQUITY $_{\text {TK }}$

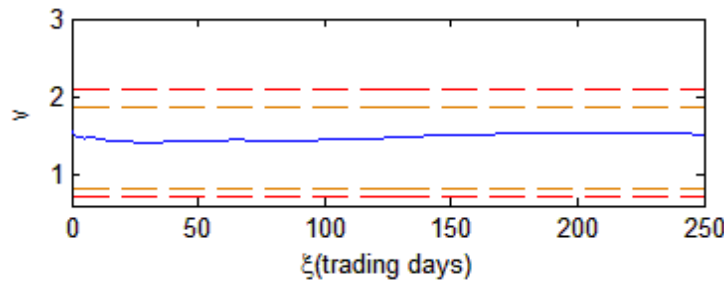



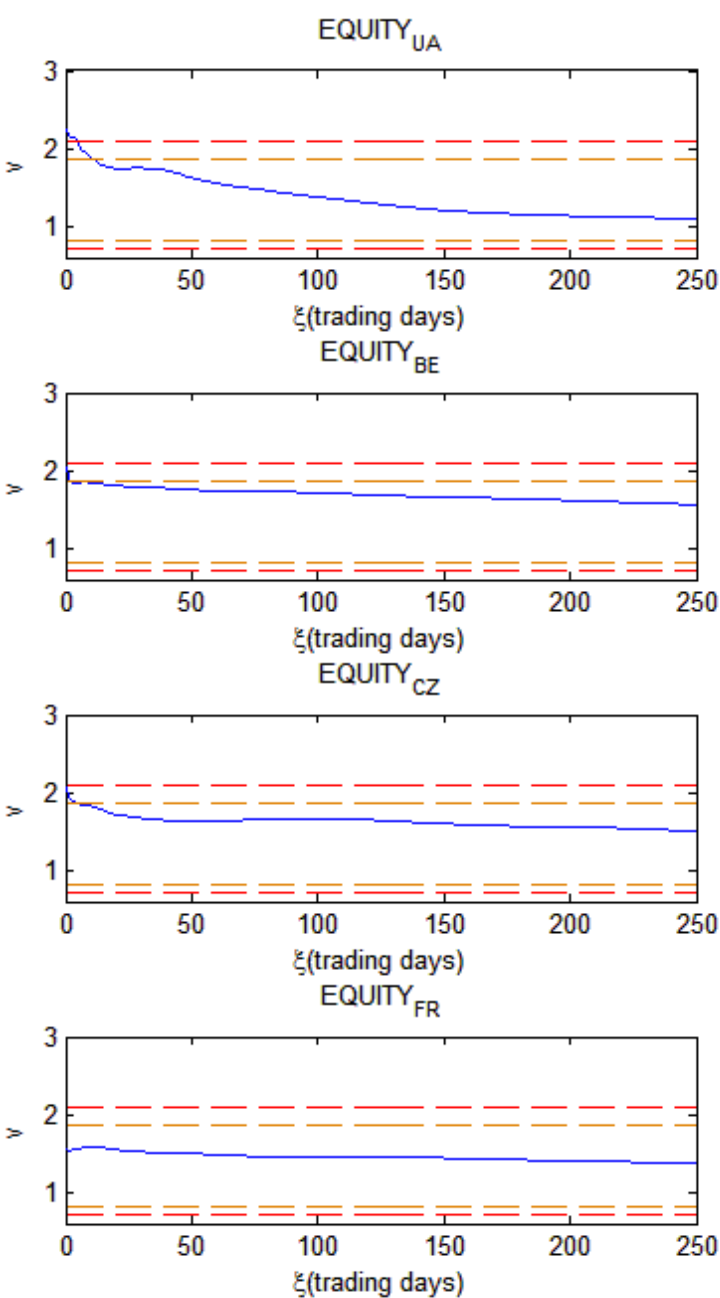
EQUITY $_{\mathrm{HU}}$

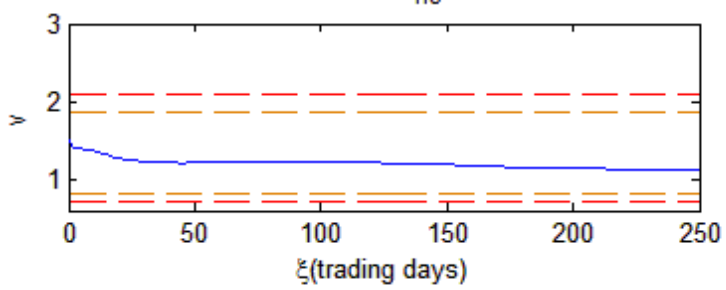
EQUITY $_{\text {JA }}$

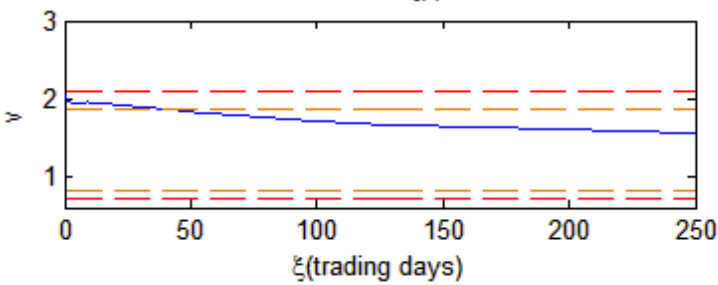

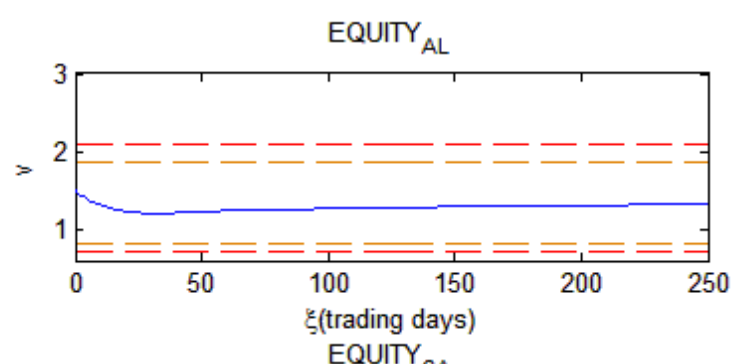
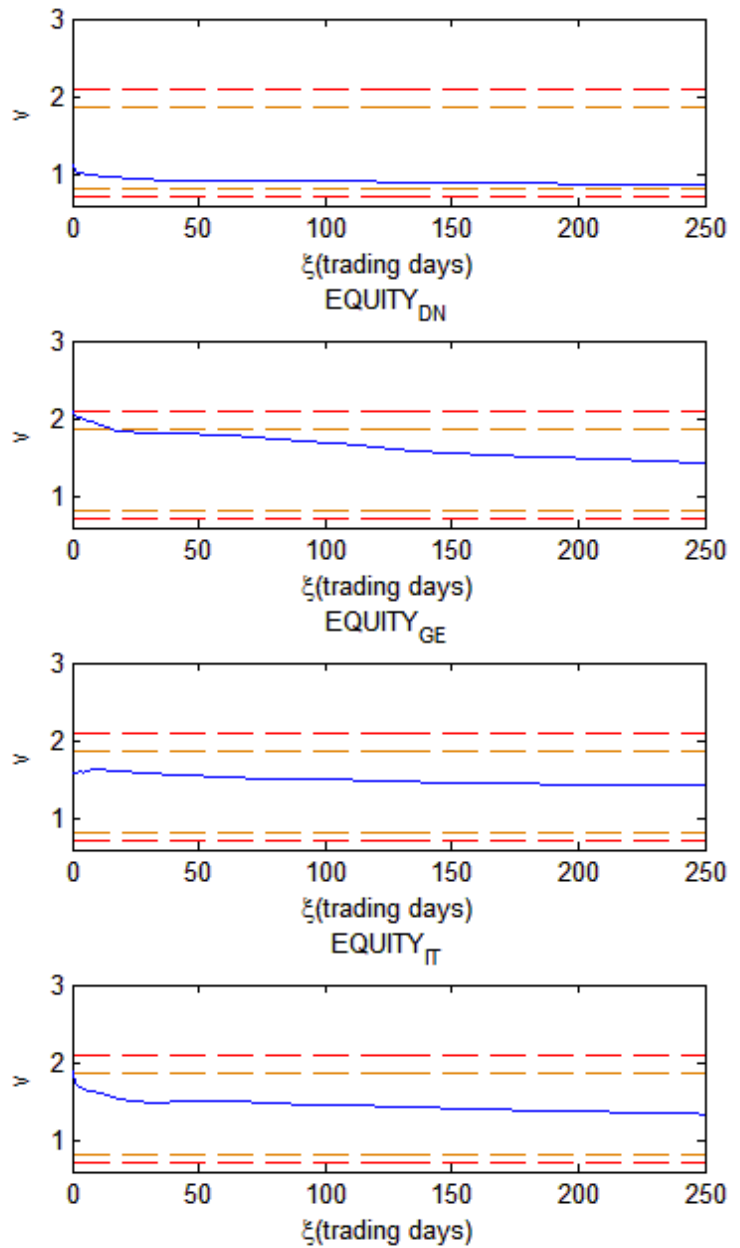
EQUITY $_{\mathrm{NE}}$

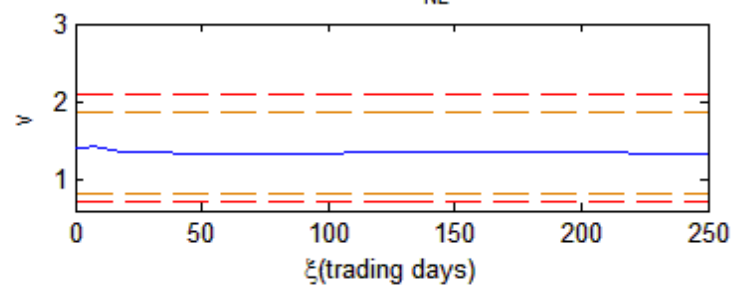



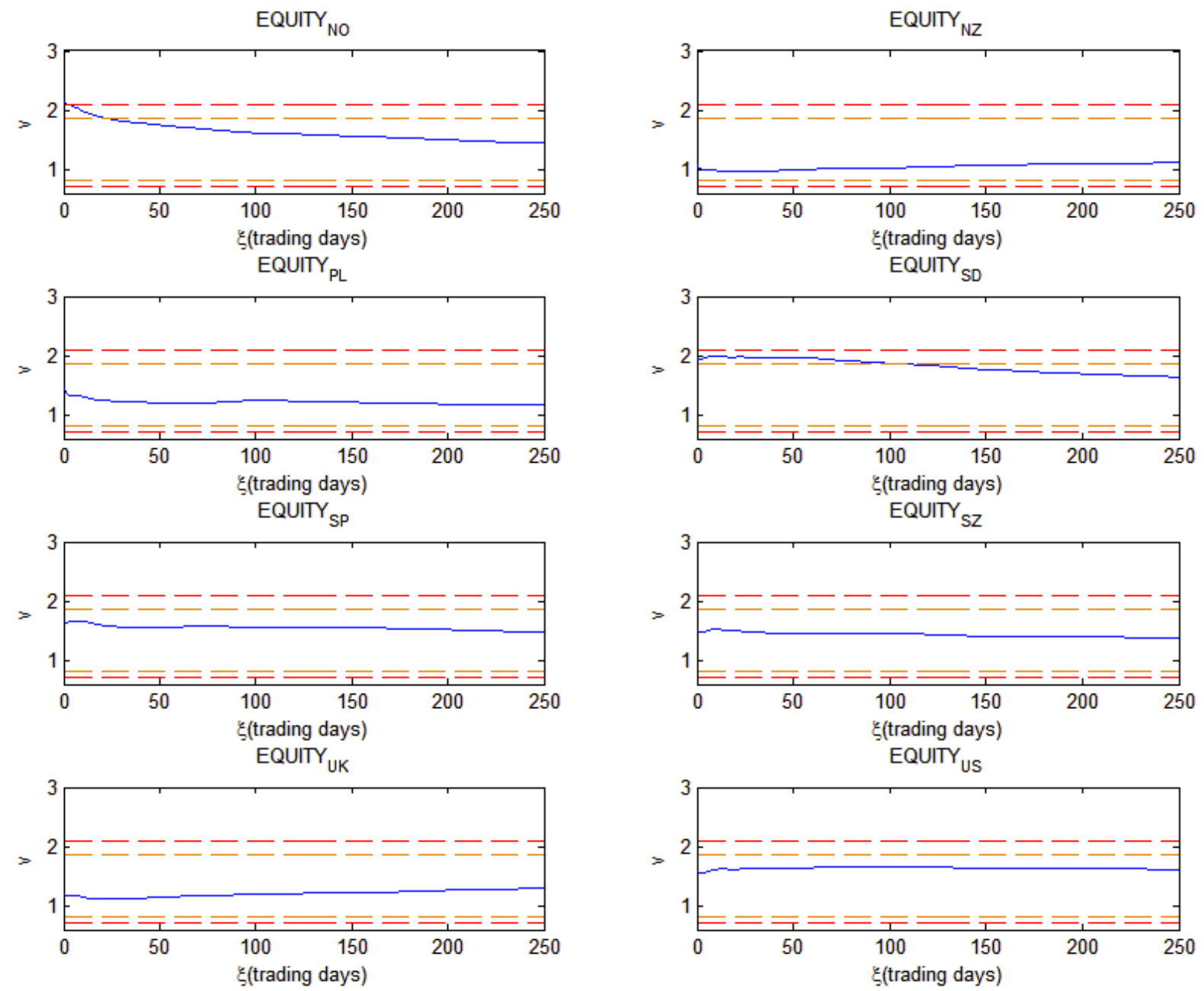

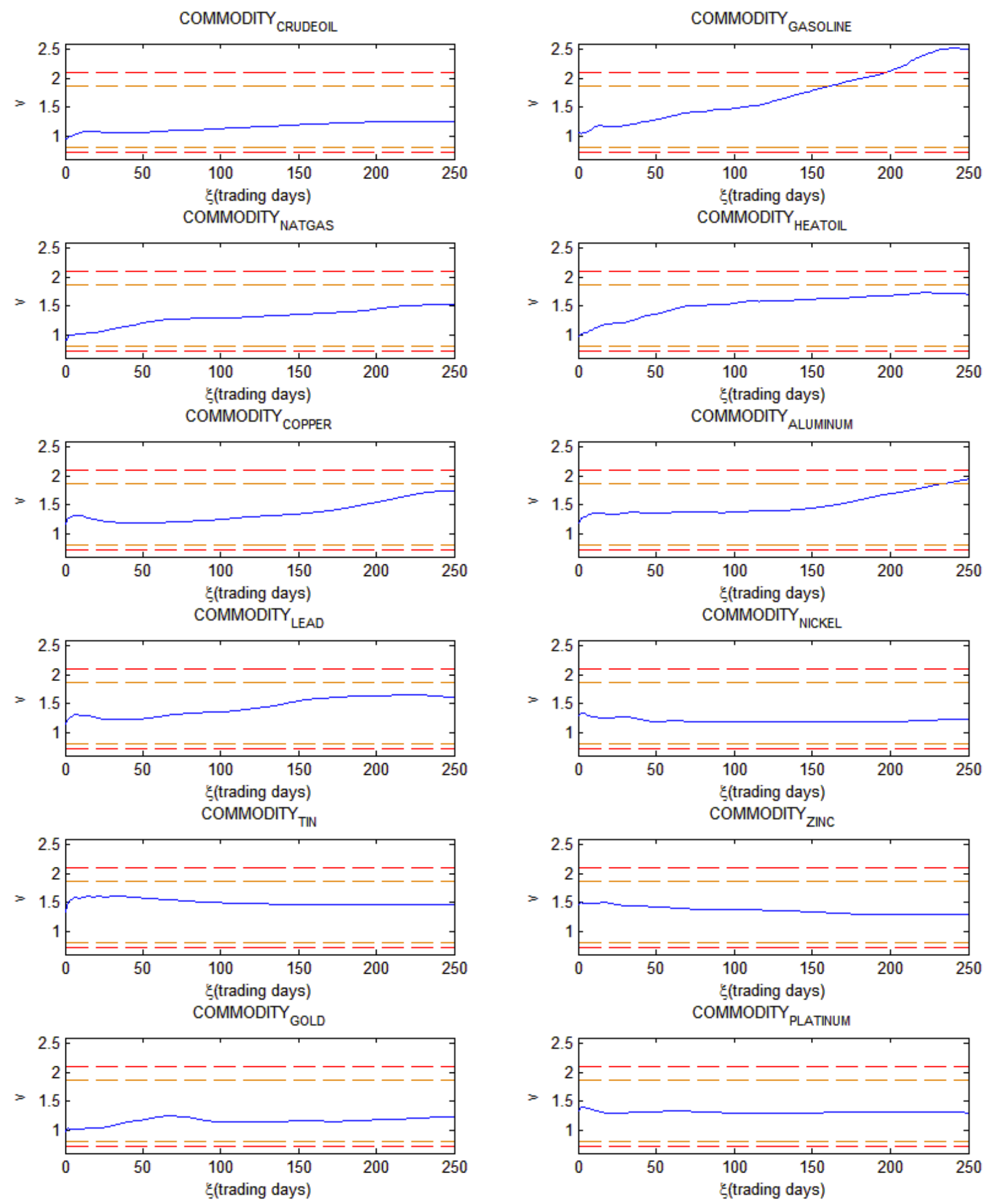

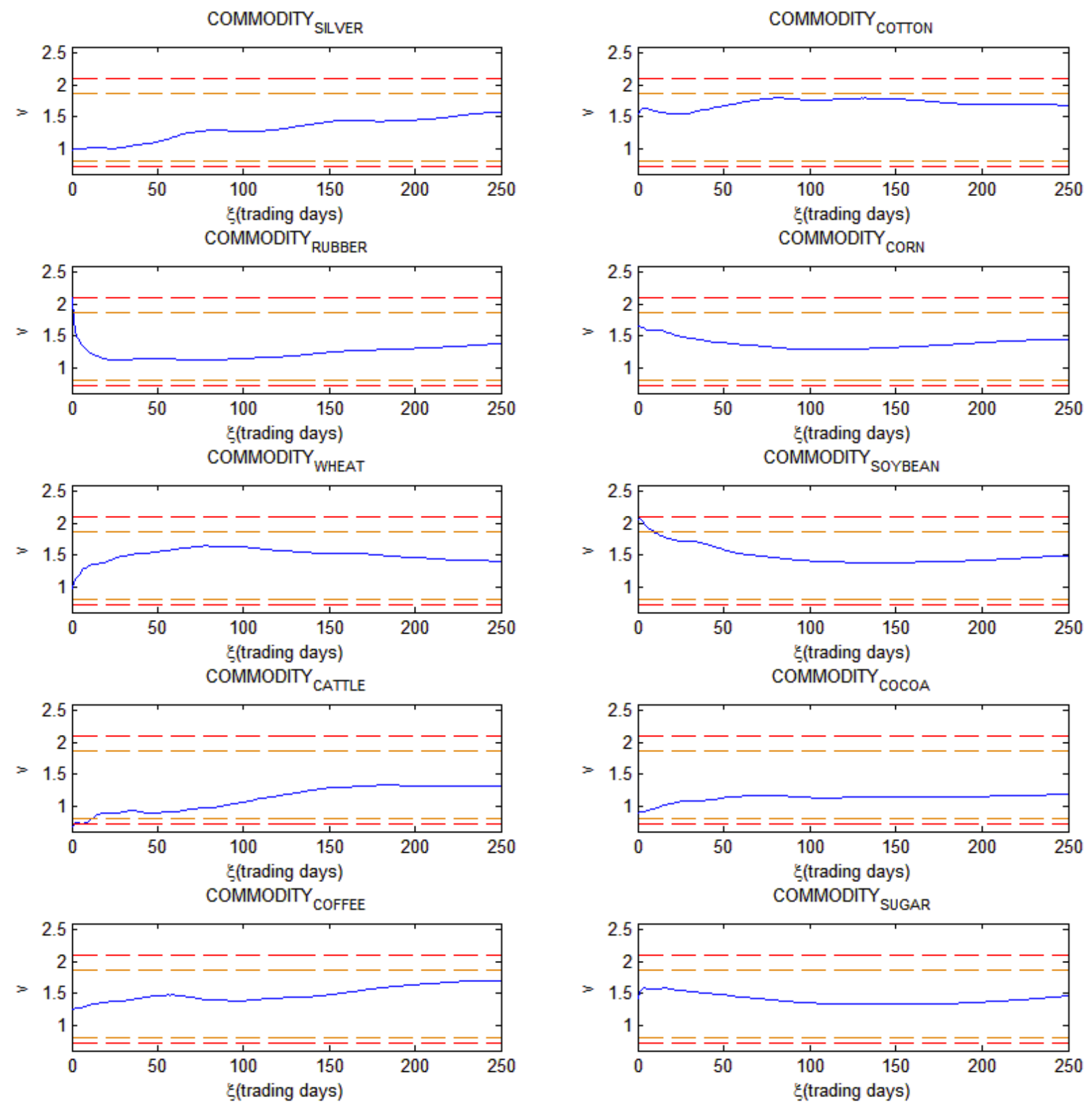

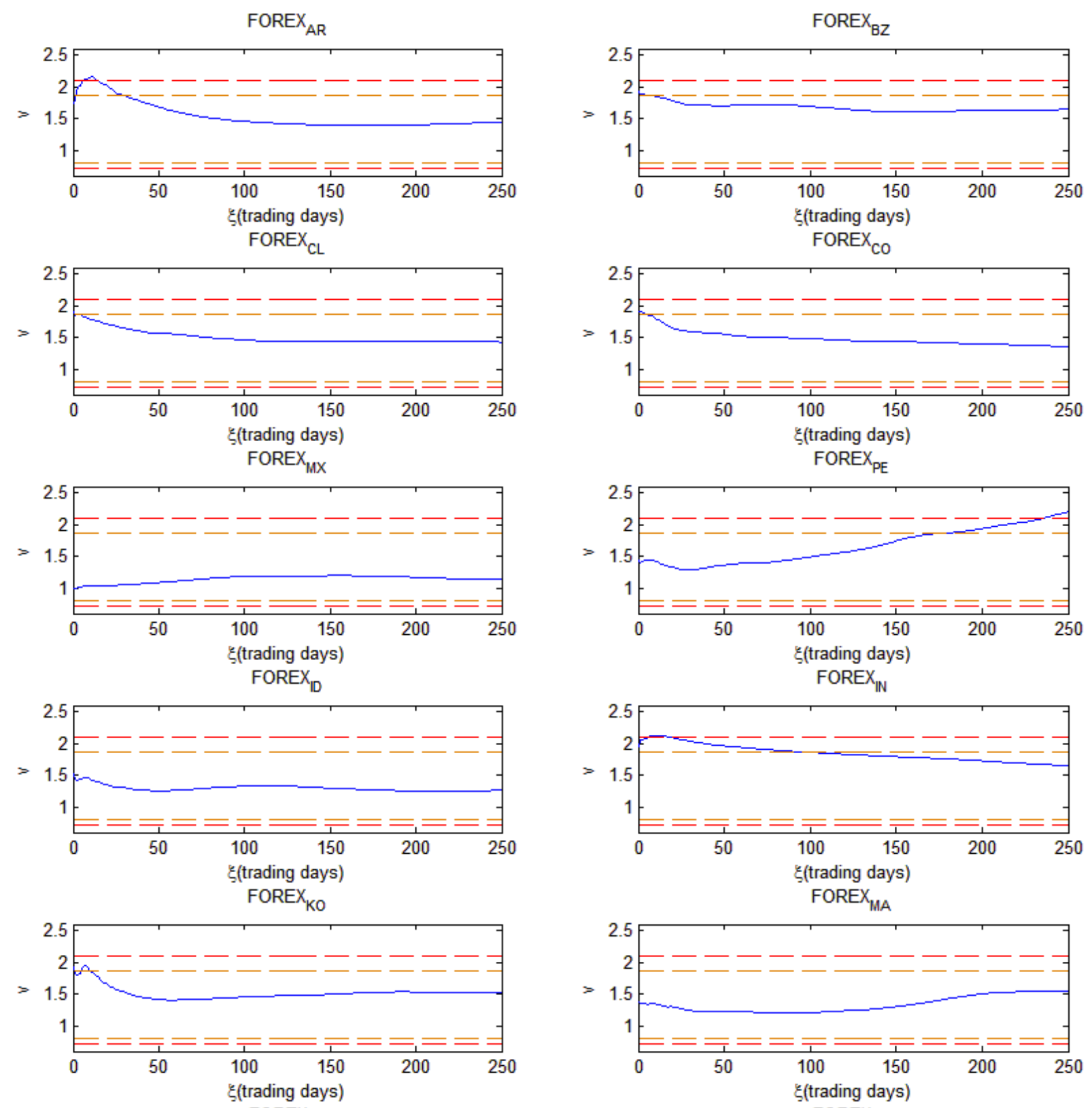

FOREX $_{\mathrm{PH}}$
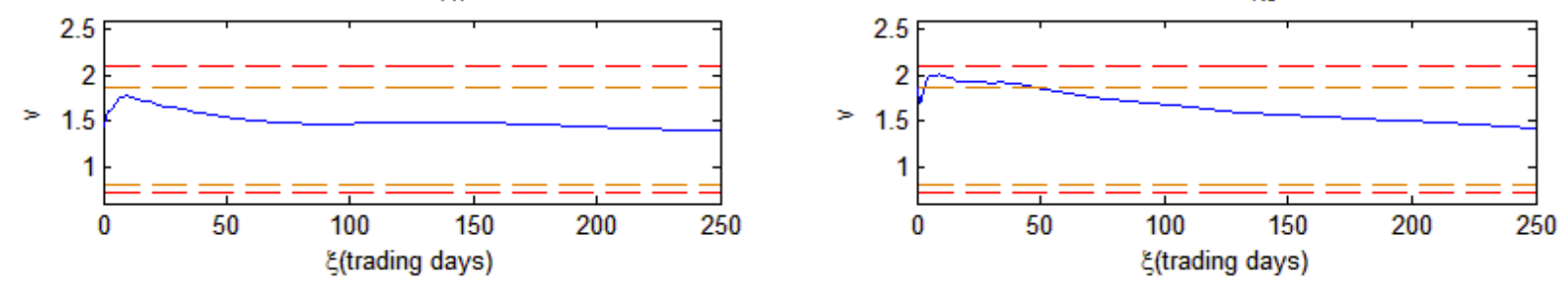

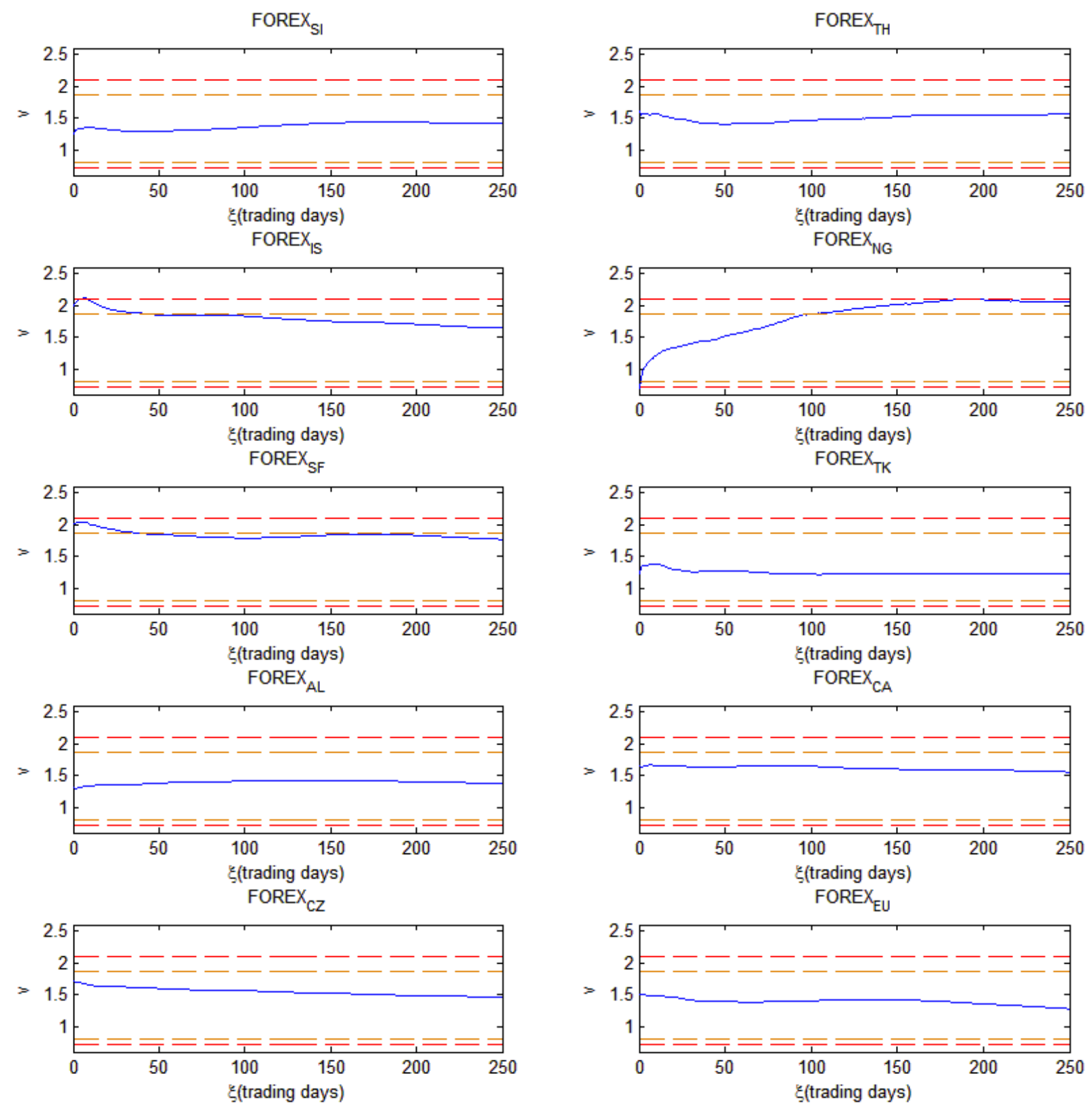
FOREX JA $_{\text {A }}$
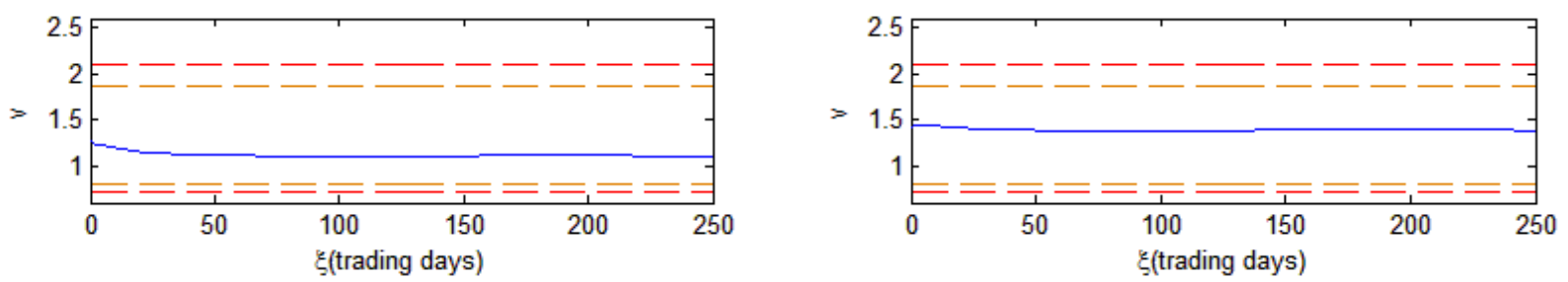
FOREX $_{\mathrm{NZ}}$

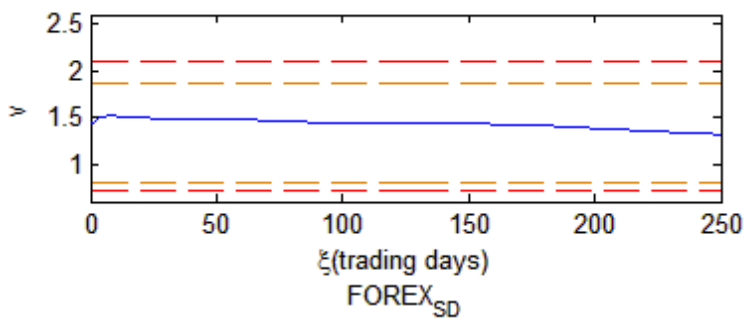

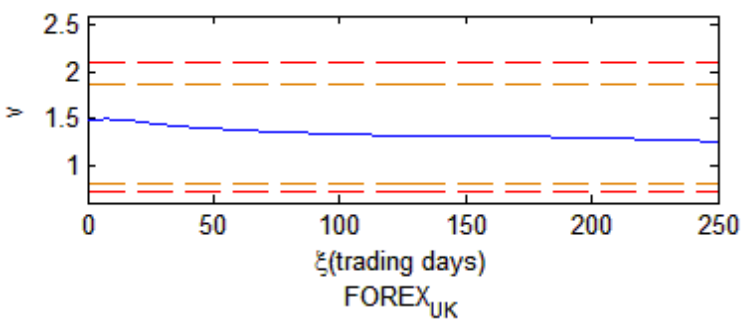

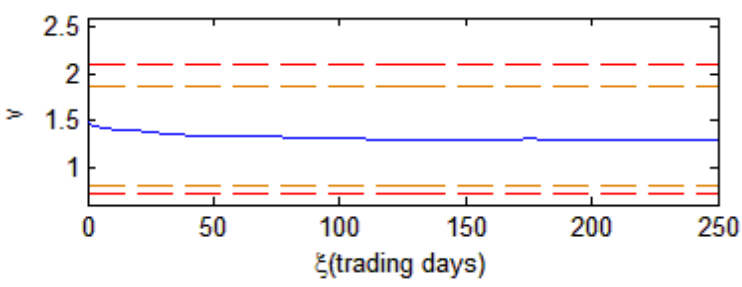

FOREX $_{\mathrm{PL}}$

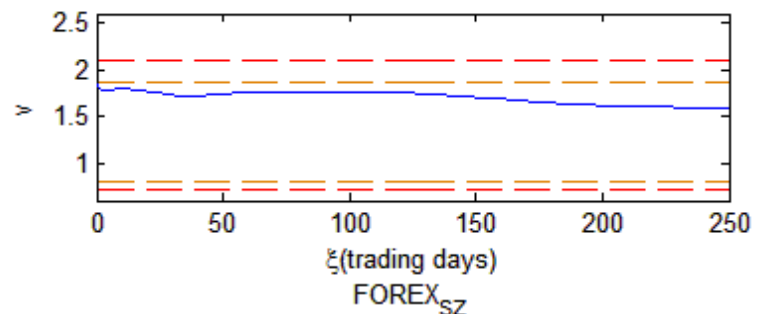
FOREX $_{\text {SZ }}$

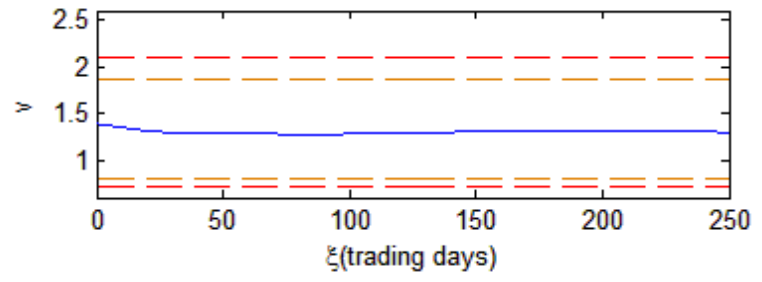

